Atmos. Chem. Phys. Discuss., 8, 17193-17235, 2008 www.atmos-chem-phys-discuss.net/8/17193/2008/ (C) Author(s) 2008. This work is distributed under the Creative Commons Attribution 3.0 License.

\title{
Observing three dimensional water vapour using a surface network of GPS receivers
}

Three dimensional water vapour from

GPS

S. de Haan and

H. van der Marel

Title Page

Abstract

Introduction

Conclusions

References

Tables

Figures

14

I

4

Back

Published by Copernicus Publications on behalf of the European Geosciences Union.

Full Screen / Esc

Printer-friendly Version

Interactive Discussion 


\section{Abstract}

Atmospheric water vapour is highly variable both in space and time. In an operational sense, only radiosonde provide vertical information on water vapour. Radiosondes are generally launched two to four times per day at synoptic times and sample primarily

5 synoptic scales. For nowcasting purposes these observations are very valuable but obviously lose their importance with elapsing time. Water vapour observations from a surface network of Global Positioning System (GPS) receivers can fill this information gap. In this paper, a GPS network is used to observe integral water vapour quantities along the line of sight, so-called Slant Water Vapour (SWV). Using a variational technique (3DVAR) a three-dimensional water vapour field is reconstructed and its performance is investigated by assimilating SWV observations deduced from a simulated atmosphere (so-called nature run). The forecasts from a high resolution limited area model (HIRLAM) embedded in the synthetic atmosphere of the nature run is compared to the separate GPS-3DVAR estimates. This experiment showed that assimilation of

15 SWV resulted in a smaller bias and standard deviation than the HIRLAM forecast with the nature run. Besides simulated data, real SWV observations are used to assess impact. Two experiments were conducted; one with a HIRLAM six hour forecast as a background field (updated every six hours) and one with persistence as background (updated every hour). The first experiment showed a reduction of the bias between radiosonde observations compared to HIRLAM forecast. The second experiment, which has no information inherited from HIRLAM, showed to have smaller biases with independent radiosonde observations than the HIRLAM analysis. The used network, however was too sparse to detect water vapour inversions correctly.

\section{Introduction}

25 Currently, radiosonde observations are one of the few information sources for upper tropospheric humidity (i.e. water vapour). These observations are sparse in time and

Three dimensional water vapour from GPS

S. de Haan and

H. van der Marel

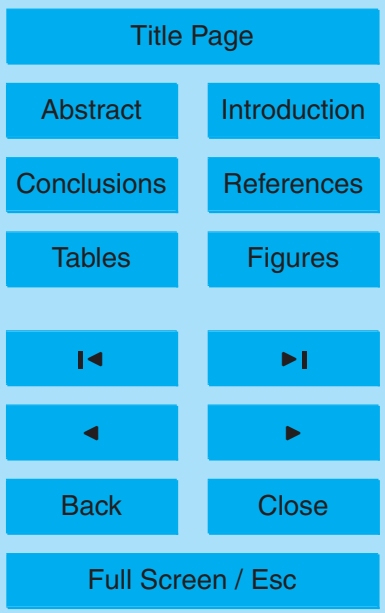

Printer-friendly Version

Interactive Discussion 
space and expensive to deploy. The current measurements of atmospheric water vapour by radiosonde networks do not posses either the temporal nor the spatial resolution to infer information about atmospheric scales smaller than synoptic scale. Imagery from geostationary satellites provides continuous monitoring of the atmospheric 5 water vapour, but the use of these observations in numerical weather prediction (NWP) is far from straightforward due to the problems with height assignment of the observed structures and with clouds.

Global Positioning System (GPS) Zenith Total Delay (ZTD) observations contain integrated water vapour (IWV) path information which can be used in NWP models and 10 forecasting applications. The temporal resolution of GPS ZTD is in the order of 15$60 \mathrm{~min}$, which is a significant advantage over radiosonde observations. High temporal water vapour measurements are likely to have a large impact on forecasting rapidly developing weather systems (de Haan et al., 2002, 2004). However, at best GPS ZTD can only provide two-dimensional integrated water vapour fields, and lacks information on the vertical distribution of water vapour.

MacDonald et al. (2000) showed that three-dimensional analysis of slant integrated water vapour can be used to construct a three-dimensional water vapour distribution. Single path phase delays can be obtained from GPS double differences (Alber et al., 2000). The root mean square errors of this method are $1.3 \mathrm{~kg} \mathrm{~m}^{-2}$ (in IWV content) 20 where the "normal" content is approximately $30 \mathrm{~kg} \mathrm{~m}^{-2}$ near zenith. At low slant path elevations angles ( $10^{\circ}$ or less) a root mean square error of $9.1 \mathrm{~kg} \mathrm{~m}^{-2}$ is observed, see Braun et al. (2001). The errors increase with decreasing elevation due to the contributions of ground reflected multipath and antenna phase centre errors.

In this paper, GPS data of the AGRS (Active GPS Reference System) network complemented with a number of International GPS Service (IGS) stations are processed at the Delft institute for Earth Oriented Space Research (DEOS) of Delft University of Technology (TUD). Timeseries of the tropospheric delay estimates are calculated from this network every $10 \mathrm{~min}$ with a standard deviation in the integrated water vapour of $2 \mathrm{~kg} \mathrm{~m}^{-2}$ (Baltink et al., 1998). These errors satisfy almost the WMO requirements for

Three dimensional water vapour from GPS

S. de Haan and

$\mathrm{H}$. van der Marel

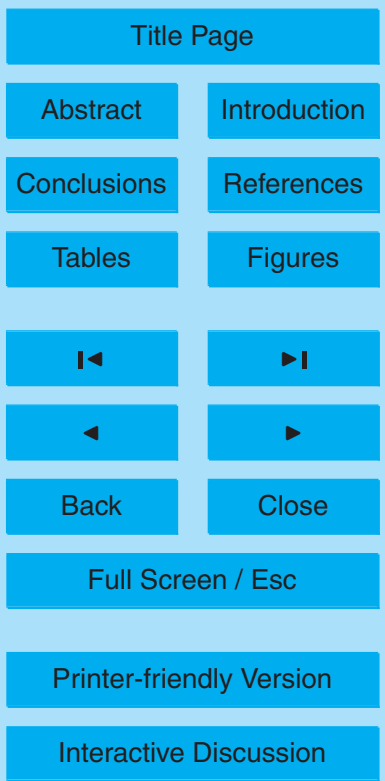


use of water vapour measurements, which are 5\% of IWV (CBS-WMO, 1996).

Instead of obtaining zenith quantities, IWV can also be measured along a slant path from a ground-based receiver to a GPS satellite. By using not only the zenith IWV of a receiver but also the slant IWV's the number of observations will increase by roughly

5 a factor ten. A slant IWV on its own has a two-dimensional character. However, by applying tomographic (Nilsson et al., 2007) or variational algorithms (Liu et al., 2007) a three-dimensional water vapour field can be retrieved from slant observations from a network of receivers. Furthermore, the horizontal resolution of the retrieved water vapour field will also profit from this larger amount of observations.

10 In the approach presented here a three-dimensional water vapour field is reconstructed using a three-dimensional variational method with real data. The approach presented here is different from Liu et al. (2007) in the sense that we do not use flowdependent background errors. The results from Liu et al. (2007) show that the retrieval improves using flow-dependent background error especially for fine-scale structures. 15 The data used here are not able to detect such fine-scale structures and therefore flow-dependency of the error structure will have a minor effect on the results presented here. Ha et al. (2003) showed that in a simulated environment, slant information from GPS can improve the temperature and moisture structure in a convectively stable region. The current study will focus on the real GPS SWV data and compare it with the results from simulation studies. Järvinen et al. (2007) showed that the HIRLAM NWP assimilation system is able to extract the asymmetric information from the slant delay observations. The variational assimilation system used in this study uses not the full atmosphere but has only water vapour as atmospheric parameter. This implies a simplification of the assimilation technique.

This paper is organised as follows. First the method of observing IWV and SWV from GPS observations is explained. Next the variational analysis system is explained and the background error covariances are presented. The section hereafter shows the results of two types of experiments: an analysis with simulated observations and an analysis with real SWV observations.

Three dimensional water vapour from GPS

S. de Haan and

H. van der Marel

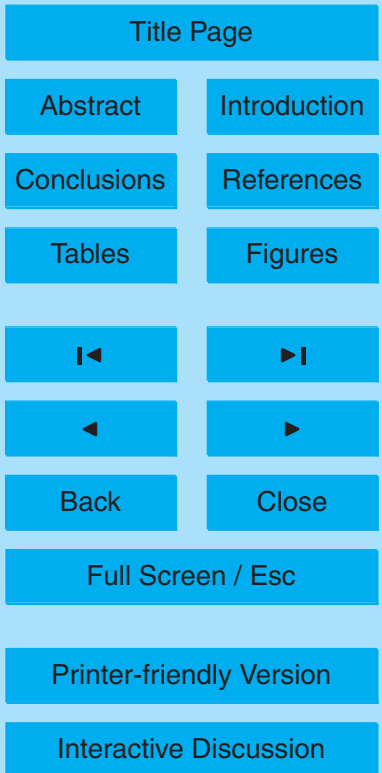




\section{Water vapour observations from GPS}

A GPS receiver measures the delay of the GPS signal for every GPS satellite in view. By processing all observed delays within a certain time window errors and unknowns, such as satellite and receiver clock errors, position of the receiver, atmospheric delay 5 and ionospheric delay, can be estimated or eliminated. The ionospheric delay in particular is eliminated by using a linear combination of observations on two different carrier frequencies. The receiver and satellite clock errors are often eliminated by forming so called double differences between satellites and receivers. The other parameters, including atmospheric delay parameters in the form of zenith total delays, are estimated from a network of GPS receivers using a least-squares inversion process.

The atmospheric delay along the signal path is due to refraction and bending, using Fermat's principle,

$\delta L=\int_{S} n d s-G+\delta S \approx \int_{S}(n-1) d s$,

where $n$ is the refractive index, $G\left(=\int_{s} d s\right)$ is the geometric distance and $\delta S$ the effect of bending; the latter can be neglected for elevation higher than $10^{\circ}$. The refractivity is defined as $N=10^{6}(n-1)$ and can be approximated by

$N=k_{1} \rho R_{d}+\left(k_{2} R_{v}-k_{1} R_{d}+k_{3} R_{v} T^{-1}\right) \rho_{w}$,

where $\rho$ is the density of air, $\rho_{w}$ is the water vapour density, $T$ is the temperature and $k_{1}, k_{2}$ and $k_{3}$ are constants (see Thayer, 1974). The Zenith Hydrostatic Delay (ZHD)

and Zenith Wet Delay (ZWD) are now defined as

$\mathrm{ZHD}=10^{-6} \int_{z} k_{1} \rho R_{d} d z$ and ZWD $=10^{-6} \int_{z} R_{v}\left(k_{2}-k_{1} R_{d} R_{v}^{-1}+k_{3} T^{-1}\right) \rho_{w} d z$

The observed delay in the line of sight, or slant total delay, is

STD $=m_{h}(\beta)$ ZHD $+m_{w}(\beta)$ ZWD

Three dimensional water vapour from GPS

S. de Haan and

$H$. van der Marel

Title Page

Abstract

Introduction

Conclusions

Tables

References

Figures

14

4

Back

Full Screen / Esc

Printer-friendly Version

Interactive Discussion 
with $m_{h}$ and $m_{w}$ the so called hydrostatic and wet mapping functions, which express the relation between slant and vertical atmospheric delay.

An estimate of the Zenith Total Delay (ZTD) for each receiver, which is the sum of ZHD and ZWD, is obtained along with other parameters in the GPS estimation process, 5 whereby the mapping functions are assumed to be known. The ZHD can be approximated using the surface pressure (Saastamoinen, 1972) and is denoted as ZHD Saas. The ZWD is associated with the vertically integrated column of water vapour overlying the GPS receiver

IWV $=\frac{1}{k}\left(Z T D-Z_{\text {Saas }}\right)$

10 where $k$ depends on the weighted mean temperature of the atmosphere $T_{m}$. The $T_{m}$ can be approximated as a linear function of the surface temperature (Davis et al., 1985; Bevis et al., 1994; Baltink et al., 2002)

Data from the network shown in Fig. 1 (denoted by the stars) are processed using Bernese GPS processing software (Rothacher and Mervart, 1996) with final orbits. 15 The GPS data used in this study have a temporal resolution of $30 \mathrm{~s}$. In the processing the minimum elevation is set to $10^{\circ}$. The ionospheric free linear combination of GPS carrier phase observations are used as observations. The clock errors are eliminated using double differences. The station positions are estimated once per day and ZWD parameters are estimated every 20 min using a least-squares inversion of the double differenced ionosphere free linear observations, using an elevation dependent weighting scheme for the observations and proper modelling of the correlations introduced by the double-differencing process.

The Slant Total Delay is computed by (van der Marel and Gündlich, 2006)

$\mathrm{STD}=m_{h}(\beta) \mathrm{ZHD}_{a}+m_{w}(\beta) \mathrm{ZWD}_{e}-M(\alpha, \beta)+\delta_{\text {non-iso }}$,

25 where $m_{h}$ and $m_{w}$ are Niell hydrostatic and wet mapping functions, and $M(\alpha, \beta)$ is the multipath correction at azimuth $\alpha$ and elevation $\beta$ which is computed from the zero difference residuals $\delta_{\text {non-iso }}$ over a period of several days (de Haan et al., 2002). ZHD

Three dimensional water vapour from GPS

S. de Haan and

H. van der Marel

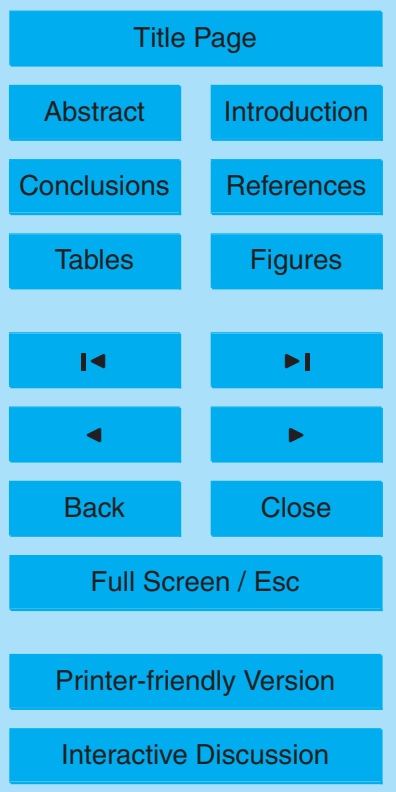


is an a priori estimate of the hydrostatic delay while $Z \mathrm{WD}_{e}$ is estimated in the processing. The zero-difference $\delta_{\text {non-iso }}$ residual is the difference between the observed ionosphere free linear combination and an ionosphere free "observation" computed from the previously determined parameters. The zero-difference residuals are com5 puted from double difference residuals, computed by the Bernese GPS software, using the procedure as outlined by Alber et al. (2000) and van der Marel and Gündlich (2006). The difference between Slant Total Delay (STD) and Zenith Total Delay (ZTD) is thus (i) STD is mapped to the slant direction, (ii) zero difference residuals are included in the STD and (iii) STD is corrected for multipath effects. Another way of writing Eq. (6) 10 is

STD $=\Phi_{\text {iono-free }}-f\left(x^{s}, x_{r}, \delta t_{r}, \delta t^{s}, A_{r}^{s}, \ldots\right)-M(\alpha, \beta)$,

with $\Phi_{\text {iono-free }}$ the ionosphere free linear combination of GPS carrier phase observations and $f\left(x^{s}, x_{r}, \delta t_{r}, \delta t^{s}, A_{r}^{s}, \ldots\right)$ the range computed from all estimated parameters except the tropospheric delays. In other words, STD is the GPS observation with all non tropospheric delay effects (including site multipath) removed, leaving only tropospheric delay.

However, the degree of freedom in the STD is smaller than the original observations as the same observations have been used to estimate the other parameters such as receiver position, satellite and receiver clock errors. In this case the satellite and re20 ceiver clock parameters are the most numerous and important, as for every epoch one clock parameter for each receiver and satellite in the network is computed (minus one for a rank defect). For a network with $R$ receivers and $S$ satellites, only $(R-1) *(S-1)$ out of $R * S$ STD observations per epoch are truly independent. The same is also apparent from the residuals $\delta_{\text {non-iso }}$ as certain linear combinations of the residuals are zero. This are exactly the same conditions as that have been used to convert doubledifference residuals into zero-difference residuals. For instance, Elosegui and Davis (2003) showed that offsets at low elevations at one site appear in the solutions at other sites of the network due to the applied differencing technique. The offset is spread over the network, although the magnitude of the spread will be relative to the value of the

Three dimensional water vapour from GPS

S. de Haan and

$\mathrm{H}$. van der Marel

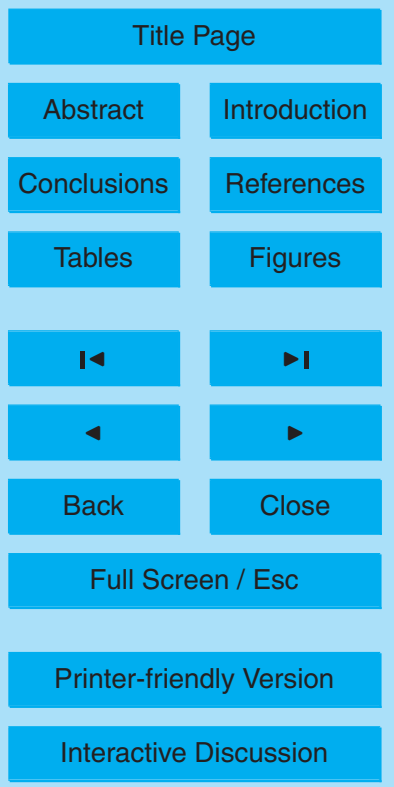


mapping functions and number of stations that have been used in the network. This effect is most severe in STD parameters that are estimated for each epoch (once every $30 \mathrm{~s}$ ), but will be reduced when the STD is averaged over time intervals of several minutes. In this paper five minute averages are used.

5 Another effect is that the STD is not truly independent of the chosen mapping functions. The mapping functions play a role in the estimation of the clock errors and other parameters, thereby, if during the GPS processing a different mapping function is adopted this will affect the other parameters and thereby propagate into the estimate of STD.

10 SWV observations are determined in a similar manner as IWV observations, with this difference that a correction for the elevation $\beta$ is applied:

$\operatorname{SWV}=\frac{1}{k}\left(\operatorname{STD}-m_{h}(\beta) \cdot \mathrm{ZHS}_{\mathrm{Saas}}\right)$

Correlated errors maybe introduced in the conversion from GPS STD to SWV. This conversion uses synoptic observations of temperature, relative humidity and pressure.

15 Because we use synoptic observations, we assume that these observations do not have systematic errors and are not correlated.

\section{Variational analysis method}

In this section the SWV analysis method is presented. To stay as close as possible to the observation, water vapour density is chosen as the state parameter and the vertical 20 parameter is in metres. The state vector will thus be water vapour density $x_{\mathrm{ijn}}\left[\mathrm{kg} \mathrm{m}^{-3}\right]$, where $i j$ are horizontal coordinates and $n$ the vertical coordinate. The integrated water vapour defined in terms of this state vector is

$\mathrm{IWV}_{i j}=\sum_{n=1}^{N} x_{\mathrm{ijn}} \Delta h_{n}$,

\section{ACPD}

$8,17193-17235,2008$

Three dimensional water vapour from GPS

S. de Haan and

H. van der Marel

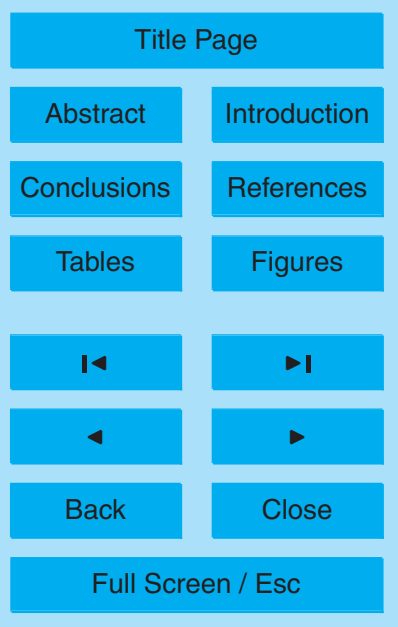

Printer-friendly Version

Interactive Discussion 
where $\Delta h_{n}$ is the layer thickness in metres. A schematic representation of the model space is shown in Fig. 2

The method to derive an estimate of the true state of the atmosphere is based on three dimensional variational technique as described in Daley (1991). The observa5 tions $\boldsymbol{y}$ are combined with a background $\boldsymbol{x}_{b}$, such that the analysed field $\boldsymbol{x}_{a}$ minimises the following cost function

$J(\boldsymbol{x})=\left(\boldsymbol{x}-\boldsymbol{x}_{b}\right)^{T} \mathbf{B}^{-1}\left(\boldsymbol{x}-\boldsymbol{x}_{b}\right)+(\boldsymbol{y}-H(\boldsymbol{x}))^{T} \mathbf{R}^{-1}(\boldsymbol{y}-H(\boldsymbol{x}))$,

where the number of observations is $K$, and the dimension of the state vector is $L$ and

$$
\begin{aligned}
& \mathbf{B}=\text { background error covariance matrix }(L \times L) \\
& \mathbf{R}=\text { observation error covariance matrix }(K \times K) \\
& H=\text { observation operator } H: \mathbb{R}^{L} \longrightarrow \mathbb{R}^{K} .
\end{aligned}
$$

10 The observation operator expresses the relation between the state space and the observations. Equation (9) is an example of an observation operator of an IWV observation. The observation operator for a SWV observation is defined as

$\operatorname{SWV}=\sum_{n=1}^{N} \frac{x\left(p_{n}\right)}{\sin \left(\beta\left(p_{n}\right)\right)} \Delta h_{n}$,

where $p_{n}$ is the position of the ray at the middle of level $n, x\left(p_{n}\right)$ is the bilinear approximation of the state of the atmosphere at level $n$ and location $p_{n}$ and $\beta\left(p_{n}\right)$ is the elevation at location $p_{n}$ and level $n$.

The observation operator $H$ is linear and thus the minimum of the cost function $J$ can be found by solving $\nabla J(x)=0$ analytically. The vector $\boldsymbol{x}$ must be non-negative (negative water vapour amounts are impossible), however it is possible that an element of the solution becomes negative. To cure this problem a simple algorithm is applied to guarantee non-negative solutions. Suppose $x_{\mathrm{ijk}}$ is negative, then the profile $x_{\mathrm{ijn}}, n=1 . . N$ is adjusted in the following manner. The negative value of $x_{i j k}$ is added to $x_{i j(k+1)}$ and $x_{i j(k-1)}$, subject to $x_{\mathrm{ijn}} \geq 0$ and the profile sum remains unchanged. Another method 17201

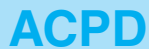

8, 17193-17235, 2008

Three dimensional water vapour from GPS

S. de Haan and

$H$. van der Marel

Title Page

Abstract

Introduction

Conclusions

Tables

References

Figures

14

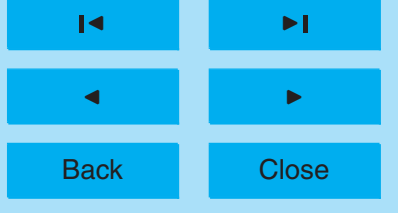

Full Screen / Esc

Printer-friendly Version

Interactive Discussion 
would be to introduce a penalty function $J_{p}(x)$ such that $J_{p}$ is small for non-negative vectors and $J_{p}$ is large otherwise. This method is not used here because any penalty function will destroy the linearity.

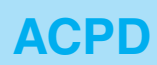

\subsection{Background error covariances}

5 One of the methods widely used to estimate the background error covariances is the method developed by Hollingsworth and Lonnberg (1986). This method uses differences between observations and forecasts fields from NWP. By studying differences between the background state vector $\boldsymbol{x}$ and observations with the same physical quantity (water vapour density) background error covariances can be examined. By com-

10 paring the difference between observations (SWV) and the model $(H \boldsymbol{x})$ observations error covariances can be examined.

A data set of 18 months of radiosonde observations from launches in the vicinity of the Netherlands and (at least) $24 \mathrm{~h}$ ECMWF forecasts from the operational 4DVAR model are selected. Radiosonde observations from De Bilt contain $10 \mathrm{~s}$ profile data; for the other radiosonde observations profile information on significant levels is used. The radiosondes selected here, other than De Bilt, had more than 25 vertical levels; the locations of the radiosonde launch sites are shown in Fig. 1 (inverse triangles).

We assume that the background error covariance matrix $C$ can be separated into a product of a function $C_{V H}$ of height $h$ and distance $r$, and a factor $f$ incorporating the behaviour of the covariance between different levels

$C\left(r, h_{1}, h_{2}\right)=C_{V H}\left(r, \frac{1}{2}\left(h_{1}+h_{2}\right)\right) \cdot f\left(h_{1}, h_{2}\right)$,

where $h_{i}$ are heights; $f$ is decreasing with increasing difference in $h_{1}$ and $h_{2}$ and $f$ is equal to 1 for $h_{1}=h_{2}$.

Radiosonde De Bilt observations measure temperature and humidity every $10 \mathrm{~s}$. This implies that roughly every $50 \mathrm{~m}$ a measurement is performed. From these measurements the water vapour amount for layers with a thickness of $1 \mathrm{~km}$ is calculated.

\section{8, 17193-17235, 2008}

Three dimensional water vapour from GPS

S. de Haan and

H. van der Marel

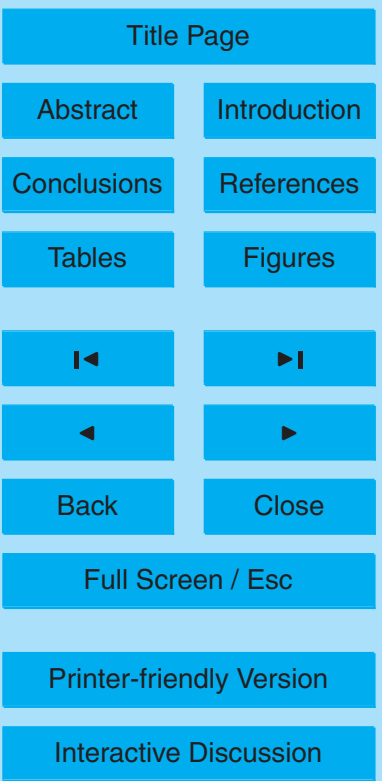

17202 
For $1 \mathrm{~km}$ levels up to $10 \mathrm{~km}$, the background error covariance with ECMWF $24 \mathrm{~h}$ forecast is shown in Fig. 3 . The maximum covariance lies around 3 to $4 \mathrm{~km}$, decaying very quickly to small numbers for levels higher than $6 \mathrm{~km}$. On the diagonal the covariance is a mixture of observation error $\sigma_{o}^{2}(h)$ and background error $\sigma_{b}^{2}(h)$. When we assume 5 that the observations are independent, the off-diagonal elements are pure background error covariances. This may of coarse not be the case, and is most likely not true here for individual observations in a profile because this profile is measured with the same equipment. However, because the layer is integrated over a height of $1 \mathrm{~km}$, we assume that the observation error covariances are small compared to the background 10 error covariances.

For the determination of the horizontal background error covariance, a similar procedure is followed as described above. Pairs of two radiosonde observation departures from the background at the same level over an 18 month period are used to determine the covariance. This covariance is plotted versus the distance between the two radiosonde launch sites. The sites used are denoted by inverse triangles in Fig. 1. In Fig. 4 the covariance-distance plot is shown for a few levels.

Each panel shows the background covariance for two levels, denoted by open circles (the lowest of the two levels) and triangles. Also shown in these panels are the variances as obtained from computation of the vertical background error covariances

\section{elements in Fig. 3.}

It turned out that an exponential decay in both vertical/horizontal covariances, as well as the function which connects different levels, resulted in a good fit. Using exponential decay of covariances is not uncommon in numerical weather prediction.

The solid and dashed lines in Fig. 4 are the fit of the data points versus the distance. Note that data with zero distance are omitted from the fitting procedure because, as said before, the variance consists of a background error part and an observation part. The function we used to fit is a function of height $h$ and distance $r$ is defined by

$$
c_{v H}(r, h)=\exp \left(a_{1}+a_{2} h+a_{3} h^{2}-\left(b_{1}+b_{2} \exp \left(b_{3} h^{2}\right)\right)^{-1} r\right) \text {, }
$$

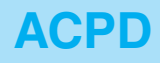

8, 17193-17235, 2008

Three dimensional water vapour from GPS

S. de Haan and

$\mathrm{H}$. van der Marel

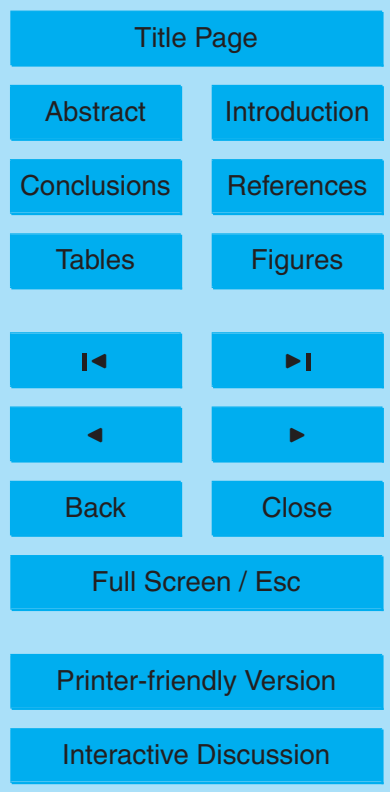


$f\left(h_{1}, h_{2}\right)=\exp \left(\left(c_{1}+c_{2}\left(h_{1}+h_{2}\right)+c_{3}\left(h_{1}+h_{2}\right)^{2}\right)\left|h_{1}-h_{2}\right|\right)$

The coefficients used are given in Table 1.

\subsection{Slant observation error covariances}

For all SWV observations from the period between 1st May and 25th May 2003 the dif5 ference between GPS-SWV and NWP-SWV is determined. A time window of one hour around the NWP valid time is chosen (i.e. plus and minus $30 \mathrm{~min}$ ). The distributions of the difference are mapped to the zenith by the Niell wet mapping function; these are shown in Fig. 5 for four selected sites. Extreme outliers are immediately detected. For example APEL has a number of negative mapped differences around -20 and $10-30 \mathrm{~kg} \mathrm{~m}^{-2}$. These outliers occur also at other sites (TERS has some outliers which are around $10 \mathrm{~kg} \mathrm{~m}^{-2}$ ). BORK (not shown here) and EUSK still have a skew distribution due to the antenna problems (van der Marel and Gündlich, 2006). For these two sites, the difference between NWP forecast and GPS SWV is more complicated than a bias multiplied by the Niell wet mapping function. Apart from these two stations, the bias between NWP SWV and GPS SWV can be denoted as a site-dependent constant multiplied by the Niell wet mapping function. The mapped difference can be expressed by a normal distribution with a site-dependent bias and a standard deviation of around $2.5 \mathrm{~kg} \mathrm{~m}^{-2}$ based on a sample rate of $30 \mathrm{~s}$ which is larger than the IWV standard deviation (approximately $2 \mathrm{~kg} \mathrm{~m}^{-2}$ ); the latter is based on a $10 \mathrm{~min}$ sample rate.

\subsection{Systematic observation error correlations}

The bias in SWV observed above can be regarded as a systematic error. For an elaborate study of systematic STD error correlations long time series are needed. At present, we do not have a long time series of slant total delay (or slant water vapour) estimates from GPS. We therefore focus on GPS ZTD estimates and use the relation between ZTD and SWV. The GPS ZTD data is obtained within the European COST716

Three dimensional water vapour from GPS

S. de Haan and

H. van der Marel

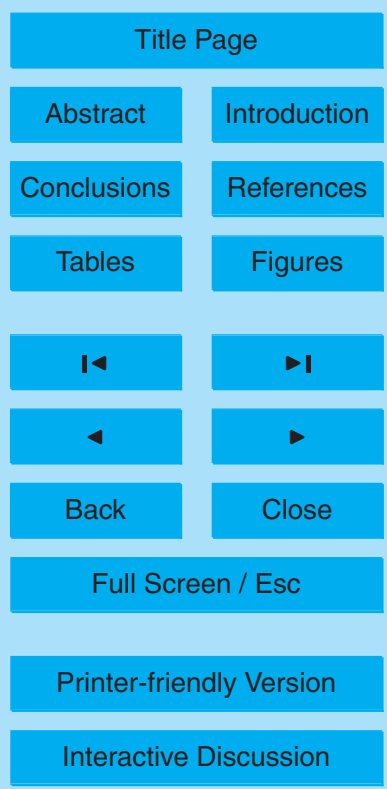


action (Elgered et al., 2004) and is processed by Geo Forschungs Zentrum, Potsdam, Germany (GFZ), for which a time series of over 18 months is available. The background error covariances are again determined using ECMWF forecast fields.

In Fig. 6a GPS ZTD background error covariances are shown with respect to GPS 5 site separation and its fit. The background error decreases to zero for large distances. This implies that the GPS ZTD observation error correlations, independent of the location, are small compared to the covariance of background errors which depend on the distance.

In Fig. 6b RS ZTD the background error covariances are shown with respect to ra10 diosonde site separation. The solid line is the background error covariance fit from GPS. The difference between the background error covariance fit from GPS and radiosonde background error covariances is similar to that of the differences between the fit and the actual data as shown in Fig. $6 a$ and b. Because no offset at large distances is observed systematic ZTD error covariances are small. There can of course

be errors from day to day or even within a solution for the whole network at a certain time, but these errors are not systematic.

Based on the distributions as shown previously and the absence of a clear systematic error we assume that the observation correlation matrix $R$ is diagonal, with only elevation dependent (co)variances. In the following GPS-3DVAR experiments we took 20 a standard deviation of $2.5 \mathrm{~kg} \mathrm{~m}^{-2}$ at zenith elevation; for an SWV observation this standard deviation was set to $2.5 / \sin (\beta) \mathrm{kg} \mathrm{m}^{-2}$ for an elevation $\beta$.

\section{Variational analysis experiments}

Two types of experiments are conducted for which the quality of the analysed water vapour are assessed. Comparisons are made between the analysed water vapour 25 fields and NWP analyses and forecasts using the HIRLAM system (Undén et al., 2002). The NWP analysis is obtained through assimilation of conventional observations by the HIRLAM analysis system (version 6.2). The experiments are:

Three dimensional water vapour from GPS

S. de Haan and

$H$. van der Marel

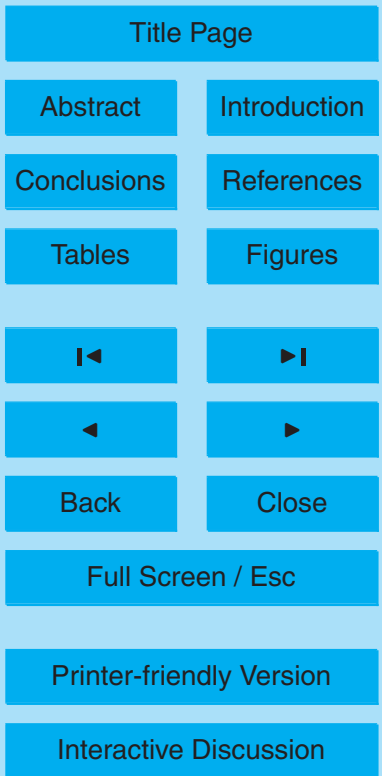


- assimilation of simulated observations by a three-dimensional variational technique. The observations are extracted from a pure synthetic atmosphere obtained from a nature run at ECMWF. The background field for the GPS 3DVAR scheme is an NWP forecast based on this nature run. These experiments are denoted as SIM-GPS,

- assimilation of real SWV observations with two different background fields:

- OBS-GPS-F: background operational NWP $6 \mathrm{~h}$ forecast

- OBS-GPS-P: background is the previous 3DVAR analysis (persistence).

To assess the additional slant information both experiments are performed with only

\subsection{Assimilation of simulated observations}

Assimilation of simulated observations can be used to assess the impact of a new observation system. Everything is simulated and thus there are almost no limitation to the observations, other than a relation between the observed parameter and the model 15 parameters should exist. Generally, an assimilation of simulated observation requires a data assimilation system, a nature run (or "truth"), and a database with simulated observations (conventional meteorological and new observations). An extensive description of the nature run and the observation database can be found in Stoffelen et al. (1994) and Becker and Roquet (1995).

20 The nature run used in this study is based on a forecast of one month of the operational global ECMWF model, performed in 1993 (Stoffelen et al., 1994; Becker and Roquet, 1995). This run is called the nature run or "truth". The vertical resolution of the nature run is 31 levels with a horizontal resolution of $110 \mathrm{~km}$. From this nature run all kinds of observations are extracted at observation locations. Realistic errors are added to these observations. Given a background field, these observations can be used in an assimilation scheme to derive the state of the atmosphere based on the (simulated) observations. Knowing the true state (i.e. the nature run) an assessment of the quality

Three dimensional water vapour from GPS

S. de Haan and

H. van der Marel

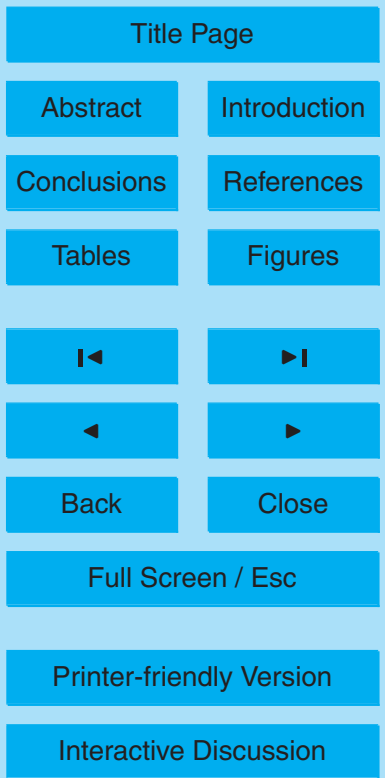

17206 
of the assimilation scheme can be made. Usually a background is a 6 or $12 \mathrm{~h}$ forecast field valid at assimilation time.

To stay as close as possible to a configuration of an operational system a special procedure is followed, avoiding the use of boundary values from the nature run in the 5 forecast. This is essential because the forecast will be used as a background in the variational analysis of GPS observations. Therefore two NWP runs, one nested in the other, are deployed. The largest uses the boundaries as determined by the nature run analysis. The smallest uses the $6 \mathrm{~h}$ forecast fields from the largest NWP run as boundaries, see Fig. 7. Because the smallest of the two lies entirely inside the largest, 10 the boundary values used for the smallest NWP can be regarded as un-coupled with the boundaries originating from the nature run.

GPS observations of SWV (and IWV) are not assimilated into the NWP system, instead the previously described 3DVAR system is fed with observations derived from the nature run, based on realistic GPS satellite configurations with additional errors as described in Sect. 3.2. The background field used for this experiment is the $6 \mathrm{~h}$ (nested) NWP forecast valid at the time of assimilation, with background error co-variance from Sect. 3.1.

In Fig. 1 the grid used for the GPS-3DVAR experiment is shown (left panel, the shaded $(3 \times 4)$ grid). The top of the SIM-GPS model is at $16 \mathrm{~km}$, much lower than the top of the atmosphere in an NWP model (which is at approximately $25 \mathrm{~km}$ ). However, the amount of water vapour above $16 \mathrm{~km}$ is almost zero and thus the atmosphere above $16 \mathrm{~km}$ can be neglected. The choice of a coarse grid (shifted pole projection with a grid box distance of $1^{\circ}$, corresponding to approximately $110 \mathrm{~km}$ resolution) was made to stay within the resolution of the nature run. Note that the ray paths are almost 25 "solitary", implying that the distribution of the slant water vapour information will mainly be determined by the background error covariance.

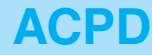

8, 17193-17235, 2008

Three dimensional water vapour from GPS

S. de Haan and

$\mathrm{H}$. van der Marel

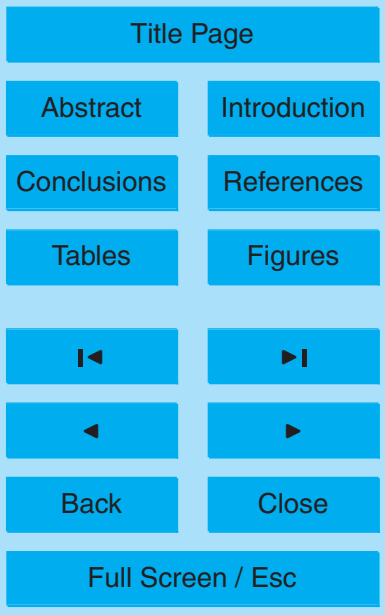

Printer-friendly Version

Interactive Discussion 
The results of one month of data from the SIM-GPS experiment are shown in Fig. 8 for three selected levels. Each panel in this figure shows, for different level heights, a scatter plot of the error in the background field (horizontal axis) versus the innovation 5 (i.e. the difference between the SIM-GPS SWV solution and the background). Ideally, the scatter plot would be the dashed straight line. From Fig. 8 we see that for the first level, from ground to $1 \mathrm{~km}$ height, the SIM-GPS innovations are more or less comparable to the background error although the correlation is not high. For levels higher in the atmosphere, the background error and innovation has a better correlation. This is encouraging, because the information from the simulated observations appears to be used correctly.

In Fig. 9 a comparison is shown between the nature run and solutions from SIM-GPS (SWV and IWV) and NWP (analysis and forecasts). In the left panel the bias between the nature run and SIM-GPS (solid lines) and NWP (dashed lines) for one month is shown over the whole three-dimensional area for which the SIM-GPS experiment was set up. The right panel shows the standard deviation between the nature run and the GPS and NWP solution. From this figure we see that NWP analysis and NWP forecast have nearly the same standard deviation and bias with respect to the nature run. The bias of SIM-GPS (both SWV and IWV) is slightly more positive than is observed for NWP analysis and forecast. The standard deviation of SIM-GPS is smaller compared to NWP analysis and forecast. Note that the forecast is used as background in SIMGPS. It is reassuring that the standard deviation from SIM-GPS is smaller than for the background (i.e. NWP forecast). The information from the observations is used correctly. The standard deviation of SIM-GPS (SWV) is smaller than SIM-GPS (IWV),
Three dimensional water vapour from GPS

S. de Haan and

$\mathrm{H}$. van der Marel

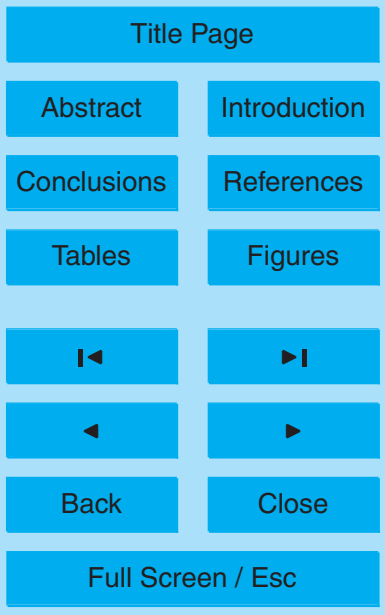

Printer-friendly Version

Interactive Discussion 
For the period from 1 May 12:00 UTC to 25 May 23:00 UTC two different OBS-GPS assimilation schemes are conducted on GPS water vapour observations. During this period an intensive observation campaign, called BBC2, was held in the Netherlands.

5 The campaign was mainly focusing on clouds, although also a large number of radiosonde observations were performed at Cabauw. These radiosonde observations were not used in the operational weather models, and can therefore be regarded as independent validation observations for both NWP model and GPS analysis system.

The background fields used in the first experiment are obtained from NWP forecasts, which allows us to compare the result with the SIM-OBS experiment previously discussed. This experiment is abbreviated as OBS-GPS-F. The second type of experiment differs from the first in the sense that the background field is now the solution of the 3DVAR system of the previous hour and the updating frequency once every hour (called OBS-GPS-P).

\section{$15 \quad 4.2 .1 \quad$ Experiments setup}

For the whole period the previously described GPS analysis system was fed by actual GPS observations. Each experiment is run twice: one run with only zenith water vapour information and one with slant water vapour information to assess the impact of slant information over zenith information.

20 The chosen horizontal grid is identical for both experiments. The horizontal grid distance is $0.3^{\circ}$, which results in grid boxes of approximately $30 \mathrm{~km}$. The vertical discretisation is in 8 levels: the first 6 levels have a $1 \mathrm{~km}$ thickness, the last two levels have a thickness of 3 and $6 \mathrm{~km}$ respectively. GPS IWV observations from processing centres GFZ and GOP (Geodetic Observatory Pecny, Pecny, Czech Republic) collected

in the COST716 NRT demonstration campaign are added. Furthermore, we have removed two sites (BORK and EUSK) due to antenna problems. The sites used for this experiment are shown in Fig. 1: stars are sites for which SWV observations are

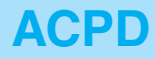

8, 17193-17235, 2008

Three dimensional water vapour from GPS

S. de Haan and

$H$. van der Marel

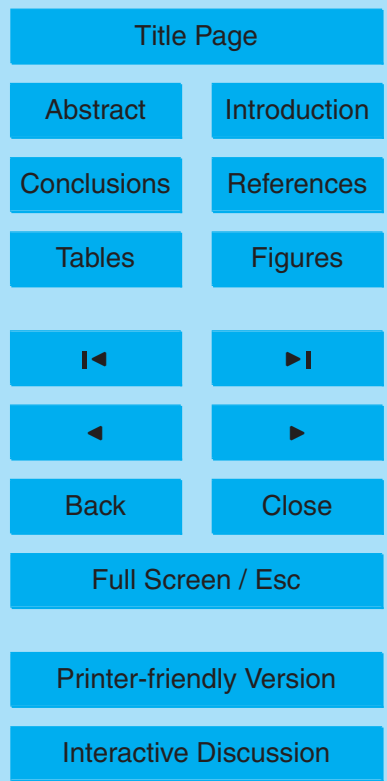


used and at the sites denoted by a solid circle IWV estimates are assimilated. Only IWV observations from GFZ and GOP are used, although IWV observations from TUD are available at all sites with SWV observations. An STD estimate was available every $30 \mathrm{~s}$. To diminish the noise of the STD observations a smoothing of the observations 5 is applied: six STD observations from the same receiver to one satellite are averaged; the standard deviation of these six STD observations mapped to the zenith should not exceed $12 \mathrm{~mm}$.

A bias correction is performed on the GPS observations. The SWV is mapped to the zenith and the bias with the state vector $\boldsymbol{x}$ obtained from NWP analysis is calculated 10 for the first two weeks of the period under consideration. The bias correction algorithm is applied because we know from previous work (Elgered et al., 2004; Ridal and Gustafsson, 2006; Poli et al., 2007) that biases exist between models and observations due to for instance differences between actual and modelled orography. SWV observations are bias corrected using the observed bias mapped to the slant by the Niell wet 15 mapping function.

\subsubsection{Experiment results with NWP background}

For this experiment, called GPS-OBS-F, the background field from operational NWP $6 \mathrm{~h}$ forecast is used. Consequently, the updating frequency is also $6 \mathrm{~h}$. This experiment is performed to obtain insight in the difference between assimilating slant observations 20 and zenith observations and to compare to the previous purely synthetic experiment. We therefore restrict the locations to those where both IWV (from GFZ and GOP) and SWV were available (the stars in Fig. 1, right panel).

The assimilation in NWP uses radiosonde information and other surface synoptic observations. The radiosonde information is only present at 00:00 and 12:00 UTC while upper atmosphere, than those at the other times (06:00 and 18:00 UTC). The $6 \mathrm{~h}$ forecast valid at 06:00 and 18:00 UTC contains information from radiosonde observations

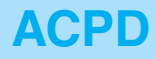

8, 17193-17235, 2008

Three dimensional water vapour from GPS

S. de Haan and

$\mathrm{H}$. van der Marel

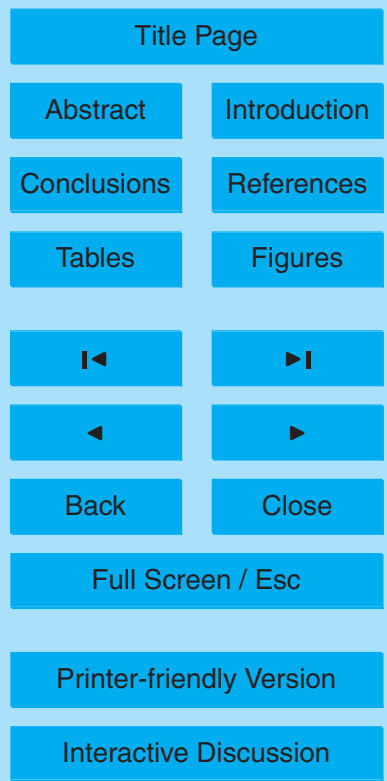

Interactive Discussion 
although this information is advected and spread.

In Fig. 10 the statistics are shown for the difference at two time pairs between NWP analysis and OBS-GPS-F SWV (solid lines with circles), IWV (solid lines) and NWP 6-h forecast (dashed line). In the left panel the statistics of the comparison is shown at 5 00:00 and 12:00 UTC; the right panel shows the differences at 06:00 and 18:00 UTC. The bias between SWV and IWV is small and the standard deviation is comparable to the standard deviation of the background. The bias of the background is larger than both OBS-GPS-F solutions. The NWP analysis at 00:00 and 12:00 UTC contain information of radiosonde observations; the bias between NWP $6 \mathrm{~h}$ forecast and NWP analysis is the result of the analyses of new radiosonde information.

A different figure is obtained when the statistics are determined for 06:00 UTC and 18:00 UTC, see Fig. 10 (right panel). Most striking in this figure is the difference between the standard deviation of the background and OBS-GPS-F (both SWV and IWV). The analyses at these times have no upper level humidity observations and are thus of lower quality. Note also that the standard deviation between NWP analysis and OBSGPS-F are equal at the surface level. The biases at the surface are more negative than shown in Fig. 10 (right panel). At the majority of the higher levels the bias between NWP forecast and analysis at 06:00 and 18:00 UTC is smaller than at the other times. This is most likely caused by the lack of upper humidity observations at 06:00 and 18:00 UTC, and thus the analysis will stay close to the background field. Apart from the lowest level, the bias is relatively small. One should keep in mind that the quality of the background field is of major importance in any analysis scheme: a bad background will result in a bad analysis, especially when the observations are sparse and the observed quantity is very variable. For both times, the bias of OBS-GPS-F is small, apart from the surface level at 06:00 and 18:00 UTC. There is some difference in the solution of assimilation of SWV and IWV, however this difference is not very clear.

The statistics of comparisons between radiosonde observations (De Bilt and Cabauw) and NWP and OBS-GPS-F are shown in Fig. 11.

NWP and OBS-GPS fields are interpolated to the location of the radiosondes. The

Three dimensional water vapour from GPS

S. de Haan and

$\mathrm{H}$. van der Marel

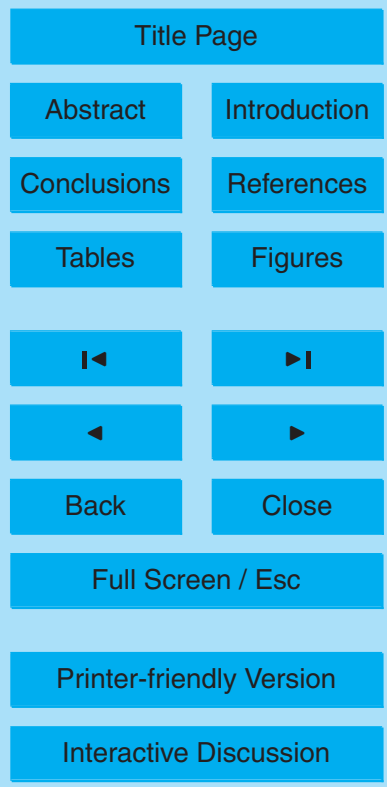


bias for radiosonde De Bilt decrease from zero to approximately -0.6 for all model types. The OBS-GPS has a bias which lies closer to zero than NWP. The standard deviation increases, as would have been expected, from top of the atmosphere to the surface. The standard deviation at the lowest two levels of NWP analysis is smaller 5 than at the others, which is not surprising because radiosonde observations are used in the assimilation of NWP. The standard deviation of OBS-GPS is comparable to NWP background. Again no large difference between OBS-GPS IWV and OBS-GPS SWV is observed. The comparison between water vapour profiles from NWP, OBS-GPS and radiosonde observation from Cabauw are shown in Fig. 11, right panel. The bias

10 of OBS-GPS lies close to the bias of the analysis for the lowest levels. The standard deviation of OBS-GPS is smaller at the lowest levels than for both analysis and forecast. Moreover, apart from the second level the standard deviation of OBS-GPS SWV is smaller than that that of OBS-GPS IWV.

Resuming, the bias against NWP analysis is small (apart from the first level at 06:00 15 and 18:00 UTC) which implies that GPS data are used in a sensible way. The bias with radiosonde however still remains and the signature at both radiosonde locations is nearly the same; the same signature is observed in the SIM-GPS experiment. The reason for this may lie in the quality of radiosonde observation or in the chosen vertical resolution. The fact that the OBS-GPS standard deviation in De Bilt is close to the background, while at Cabauw the standard deviation is smaller than the background, can be explained because a GPS antenna is installed in Cabauw: assimilation of SWV observations have a local effect.

\subsubsection{Experiment results with a persistent background}

The difference between the experiment described here and the previously described 25 experiment is the origin of the background field. Except for the first assimilation step, the solution of the GPS analysis system of the previous hour is used as the background field in the 3DVAR system. The first background field is a $6 \mathrm{~h}$ forecast of the operational NWP model (valid at 1 May 12:00 UTC).

Three dimensional water vapour from GPS

S. de Haan and H. van der Marel

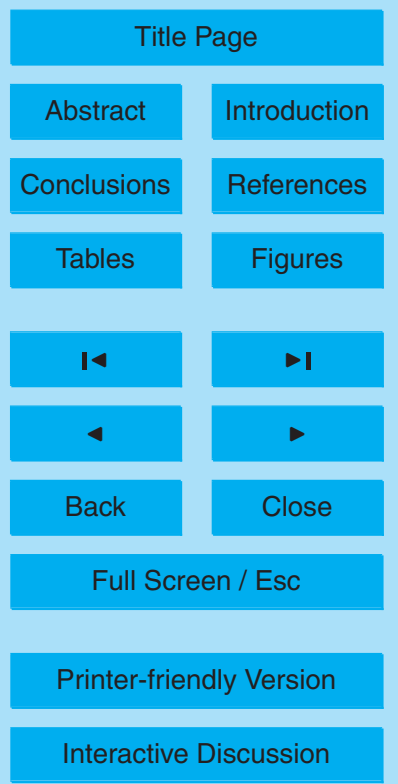


For the site Cabauw the resulting estimates at different levels are shown in Fig. 12 for the whole period under consideration. The solid line is the solution of OBS-GPS-P , the dashed line is the NWP analysis solution at the location Cabauw and the stars are the radiosonde observations from Cabauw. Figure 12 shows that the timeseries for 5 the lowest four levels of NWP, GPS and RS are close to each other. There are periods were GPS lies closer to the the largest RS observations while NWP follows the lowest observations (e.g. 10-11 May, levels $4.5 \mathrm{~km}$ and $5.5 \mathrm{~km}$ and 17-23 May, same levels). The sharp gradients observed in the radiosonde observations (e.g. 4th May, 16th May, and 20th May) are also visible in both GPS and NWP. On May 8th, two radiosonde 10 observations have a very dry layer at $1.5 \mathrm{~km}$ height, while both GPS and NWP are much wetter.

In Fig. 13 the bias and standard deviation of water vapour observations from radiosondes De Bilt and Cabauw (synoptic times) with NWP analysis, NWP forecast and OBS-GPS-P (IWV and SWV) are shown. Note that radiosonde observations from De 15 Bilt are used in the NWP analysis and thus the bias and standard deviation between radiosonde and NWP analysis are better than when compared to NWP background.

The bias and standard deviation of OBS-GPS-P SWV for De Bilt are similar to the statistics for OBS-GPS-F SWV shown in Fig. 11. The standard deviation of GPS-OBS$P$ IWV is much larger for the lowest 3 levels when an hourly persistence background 20 is used than when a NWP forecast background is used (compare the solid curves in Fig. 11 and 13). The reason for this is because no extra vertical information is introduced when only IWV observations are assimilated. SWV observations introduce extra vertical information which spread in the horizontal by the background correlation matrix and thus the whole model area will benefit from this additional information. Looking at the standard deviation at Cabauw in Fig. 13 between RS and OBS-GPS-P IWV and OBS-GPS-P SWV, one observes that both standard deviations are close, although the standard deviation at the second level is smaller for OBS-GPS-P SWV. Again, the standard deviation is larger, for both SWV and IWV with an hourly background than with a NWP forecast as background. The bias, however, is better when a hourly back-

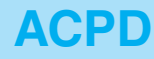

8, 17193-17235, 2008

Three dimensional water vapour from GPS

S. de Haan and

H. van der Marel

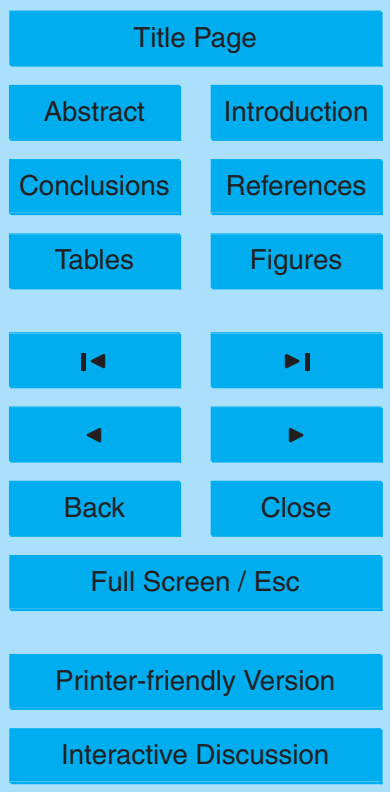


ground is used. Note that the standard deviation for GPS SWV with both radiosonde locations is comparable, indicating that the resulting three-dimensional water vapour fields have roughly the same quality over the model grid area. Furthermore, the variational run with a persistence background is completely independent from the numerical 5 model (apart from the first time step). A standard deviation comparable to the NWP background (i.e. forecast) and a better bias shows that the 3DVAR system has a good performance.

The radiosonde Cabauw is launched at different times than the normal synoptic times and comparison with the hourly OBS-GPS-P SWV/IWV results in a double number of 10 collocations, see Fig. 14. The statistics do not change very much when compared to the synoptic collocations shown in Fig. 13.

We may conclude from these figures that the SWV observations have a positive effect, although due to the horizontal distribution of the GPS receivers the effect of the extra slant observation is small. The 3DVAR system performs well due to the sites, "inversions" in $\rho_{w}$ are not determined as can be seen in Fig. 15a. For this case NWP has a local maximum in $\rho_{w}$ at the wrong height, compared to the radiosonde. An example of a profile where OBS-GPS-P SWV lies closer to the radiosonde solution than NWP is shown in Fig. 15b.

\section{Conclusions}

Despite the difficulties in interpreting slant delays the benefits of using slant total delays (STD) compared to zenith total delays (ZTD) are impressive. First of all, using slant delays one has information on gradients and non-isotropic delays in the atmosphere. Secondly when slant delays are used the part of the atmosphere that is sampled is exactly known. For example, in the Netherlands the sky is not sampled homogeneously and there is always an area in the northern sky without satellites. Moreover the satellite constellation is changing continuously, which will affect the ZTD estimation. Slant

Three dimensional water vapour from GPS

S. de Haan and

H. van der Marel

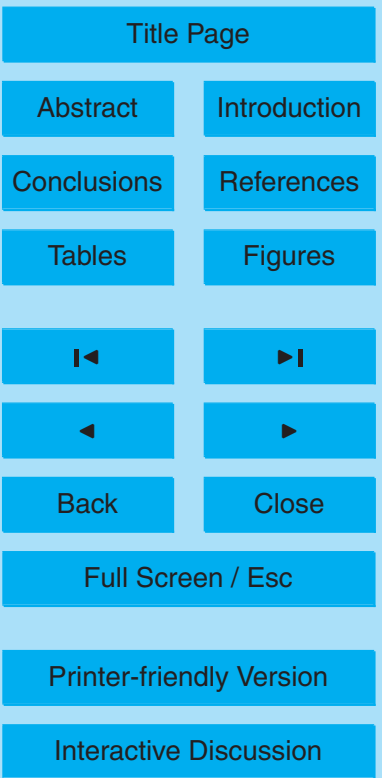


delays are much more accurate in this respect, as we know precisely the elevation and azimuth of the underlying observations. Thirdly, there are simply more STD observations than ZTD observations.

A three-dimensional variational (3DVAR) assimilation system has been developed.

5 Background error covariance matrix were constructed using 18 months of high resolution radiosonde observations. An estimate of the observations error is made, however due to the length of the current dataset an extensive investigation of the observation error covariance matrix of slant water vapour could not be performed.

Two types of experiments were presented: an assimilation of simulated SWV observation from a nature run and two experiments with real GPS SWV data.

The use of slant observations in the simulated observation assimilation experiment results in a smaller standard deviation than when only zenith observations are used; the biases are similar. Slant observations have a positive effect on the standard deviation, even though the distribution of the GPS locations is (relatively) sparse with 15 respect to the intersection between the ray-path and 3DVAR-grid. The limitation of the nature run resolution, approximately $110 \mathrm{~km}$, lays a constraint on the maximal horizontal resolution that can be resolved. The simulating observation experiment shows that the GPS-3DVAR system is capable of reconstructing the three-dimensional water vapour structures. In the lowest levels, the GPS-3DVAR system does not calculate the expected innovations perfectly. Compared to the HIRLAM-3DVAR analysis solution, GPS-3DVAR has a similar bias and better standard deviation. Note that for this experiment $6 \mathrm{~h}$ forecasts from HIRLAM-3DVAR are used as background information. Moreover, the period for which the nature run is valid is a winter period in the Northern Hemisphere, which may explain the overall small standard deviation.

25 The experiments with real data and a HIRLAM $6 \mathrm{~h}$ forecast as a background showed a similar result, although a little less positive, however because in this case real data is used the results are encouraging. Standard deviations between GPS-3DVAR solutions and Cabauw radiosonde observations are smaller than the standard deviations observed between HIRLAM analysis and radiosonde observation. When radiosonde

Three dimensional water vapour from GPS

S. de Haan and

H. van der Marel

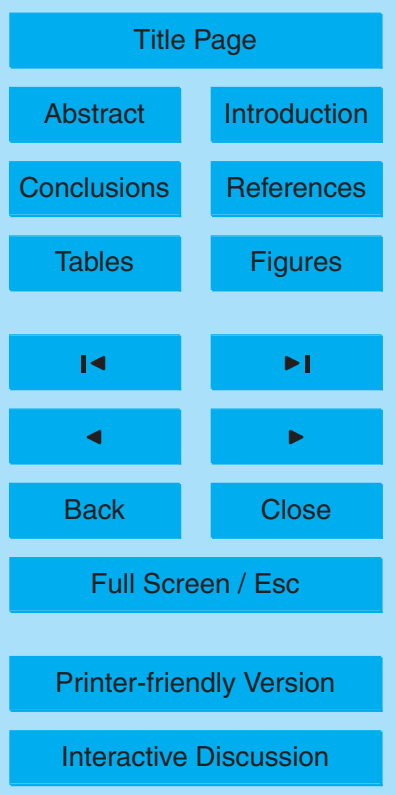

17215 
observations from De Bilt are compared to GPS-3DVAR we see that the bias improves but the standard deviations lie close to the standard deviation of the background field. In Cabauw a GPS receiver is installed; slant information from this GPS receiver has a positive impact on the GPS-3DVAR derived three-dimensional water vapour. In De Bilt, 5 no slant information was available resulting in a slightly less quality GPS-3DVAR water vapour field around this location. A small improvement of the standard deviation at a height of 2 to $4 \mathrm{~km}$ was observed when slant water vapour observations were used in stead of zenith water vapour observations. The fact that the bias between radiosonde and any other system is negative at the surface does not necessarily point towards 10 problems with the models (both NWP and GPS) but may be due to an observation bias in the radiosonde: further research is needed to understand this bias.

The last experiment presented was "stand alone" in the sense that only for the first analysis a HIRLAM background was used. All successive analysis used the previous solution of the GPS-3DVAR system as the background (persistence). The time step 15 between successive analysis is set to one hour. When only zenith observations are used a large standard deviation in the lowest $3 \mathrm{~km}$ with radiosonde De Bilt was detected. This standard deviation becomes smaller, and more in line with values found in previous experiments, when slant water vapour observations are used. At Cabauw a small decrease in standard deviation, at a height of 1 to $2 \mathrm{~km}$ is observed when the results of the assimilation of slant observations and zenith observations are compared.

Two examples of a comparison between water vapour profiles from Cabauw and NWP show that the NWP model is not always capable to "reconstruct" the correct profile. One example shows that the NWP profile has an inversion, however it is located at a wrong height. The other example shows that the amount of water vapour in the top of 25 the atmosphere is not correct. In the first example, GPS-3DVAR profile does not show an inversion at all; in the second example the profile of GPS-3DVAR is closer to the observed profile. The GPS-3DVAR system with the current distribution of (operational) GPS receivers is not capable of reconstructing strong water vapour inversions, without prior (background) or additional observations (radiosonde, water vapour radiometer,

Three dimensional water vapour from GPS

S. de Haan and $H$. van der Marel

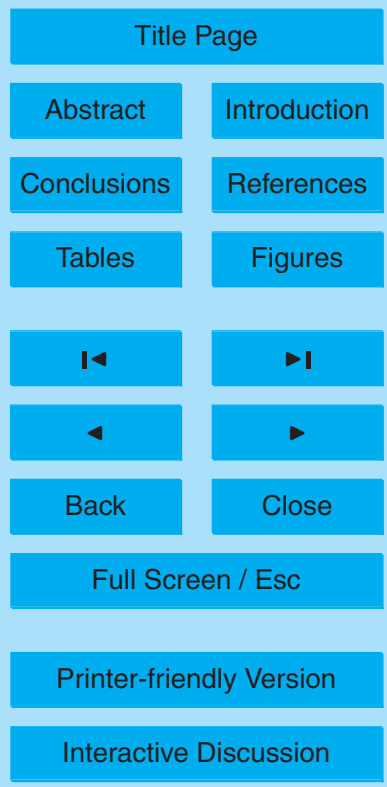

17216 
surface relative humidity). Nevertheless, the GPS-3DVAR system presented here is capable to estimate three-dimensional humidity with an accuracy comparable to a $6 \mathrm{~h}$ NWP forecast. The GPS-3DVAR system will benefit from a denser network of GPS receivers.

5 Acknowledgements. This research is sponsored by the Space Research Organisation Netherlands in the project SRON-EO-050. The organisers and participants of the BBC2 campaign are also thanked for kindly providing access to their radiosonde data. The authors would like thank analysis centres GOP and GFZ for their ZTD estimates and the anonymous IGS data providers for access to the GPS data.

\section{References}

Alber, C., Ware, R., Rocken, C., and Braun, J.: Obtaining single path phase delays from GPS double differences, Geophys. Res. Lett., 27, 2661-2664, 2000. 17195, 17199

Baltink, H. K., Derks, H. J. P., van Lammeren, A. C. A. P., Ambrosius, B. A. C., van der Hoeven, A. G. A., van der Marel, H., Kleijer, F., and Kosters, A. J. M.: GPS Water Vapor Meteorology, Tech. Rep. Report 98-27, Netherlands Remote Sensing Board (BCRS), 1998. 17195

Baltink, H. K., van der Marel, H., and van der Hoeven, A. G. A.: Integrated atmospheric water vapor estimates from a regional GPS network, J. Geophys. Res., 107, (3-1)-(3-8), aCL, 2002. 17198

Becker, B. and Roquet, H.: Extension of the OSSE database to scatterometer and ATOVS data, Final Report Part II, Tech. rep., ECMWF, Reading, 1995. 17206

Bevis, M., Businger, S., Chiswell, S., Herring, T. A., Anthes, R. A., Rocken, C., and Ware, R. H.: GPS Meteorology: Mapping Zenith Wet Delays onto Precipitable Water, J. Appl. Meteorol., 33, 379-386, 1994. 17198

Braun, J. J., Rocken, C. R., and Ware, R. H.: Validation of line-of-sight water vapor measurements with GPS, Radio Sci., 36, 459-472, 2001. 17195

CBS-WMO: Working Group on Satellites Second Session, Final Report, 1996. 17196

Daley, R.: Atmospheric data analysis, Cambridge University Press, 2nd edn., 1991. 17201

Davis, J., Herring, T., Shapiro, I., Rogers, A., and Elgered, G.: Geodesy by Radio Interferome-

Three dimensional water vapour from GPS

S. de Haan and

$\mathrm{H}$. van der Marel

Title Page

Abstract

Introduction

Conclusions

References

Tables

Figures

14

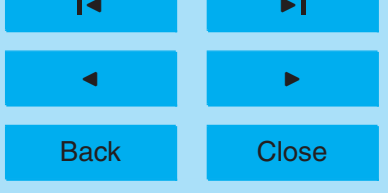

Full Screen / Esc

Printer-friendly Version

Interactive Discussion 
try: Effects of Atmospheric Modeling Errors on Estimates of Baseline Length, Radio Sci., 20, 1593-1607, 1985. 17198

de Haan, S., van der Marel, H., and Barlag, S.: Comparison of GPS Slant Delay Measurements to a Numerical Model: case study of a cold front passage, Phys. Chem. Earth, 27, 317-322, $5 \quad$ 2002. 17195,17198

de Haan, S., Barlag, S. J. M., Baltink, H. K., and Debie, F.: Synergetic use of GPS water vapor and Meteosat images for Synoptic Weather Forecasting, J. Appl. Meteorol., 43, 514-518, 2004. 17195

Elgered, G., Plag, H.-P., Barlag, S., and Nash, J.: COST716 final report, European Union, 2004. 17205, 17210

Elosegui, P. and Davis, J. L.: Accuracy Assessment of GPS Slant-Path Determination. Extended abstracts, in: International Workshop on GPS Meteorology - GPS Meteorology: Ground-Based and Space-Borne Applications, Tsukuba, Japan, pp. 1-35-1-1-36-6, 2003. 17199

15 Ha, S.-Y., Kuo, Y.-H., Guo, Y.-R., and Lim, G.-H.: Variational Assimilation of Slant-Path Wet Delay Measurements from a Hypothetical Ground-Based GPS Network . Part I: Comparison with Precipitable Water Assimilation, Mon. Weather Rev., 131, 2635-2655, 2003. 17196

Hollingsworth, A. and Lonnberg, P.: The statistical structure of short-range forecast errors as determined from radiosonde data. Part I: The wind field, Tellus, 38A, 111-136, 1986. 17202

Järvinen, H., Eresmaa, R., Vedel, H., Salonen, K., Niemelä, S., and de Vries, J.: A variational data assimilation system for ground-based GPS slant delays, Q. J. Roy. Meteor. Soc., 133, 969-980, 2007. 17196

Liu, H., Xue, M., Purser, R. J., and Parrish, D. F.: Retrieval of Moisture from Simulated GPS Slant-Path Water Vapor Observations Using 3DVAR with Anisotropic Recursive Filters, Mon. Weather. Rev., 135, 1506-1521, 2007. 17196

MacDonald, A. E., Yuanfu, X., and Ware, R. H.: Diagnosis of Three-Dimensional Water Vapor Using Slant Observations from a GPS Network, in: COST 716 Action Workshop, Oslo, 2000. 17195

Nilsson, T., Gradinarsky, L., and Elgered, G.: Water vapour tomography using GPS phase observations: Results from the ESCOMPTE experiment, Tellus, 59A, 674-682, 2007. 17196

Poli, P., Moll, P., Rabier, F., Desroziers, G., Chapnik, B., Berre, L., Healy, S. B., Andersson, E., and Guelai., F.-Z. E.: Forecast impact studies of zenith total delay data from European near real-time GPS stations in Météo France 4DVAR, JGR, 112, 2007. 17210

Three dimensional water vapour from GPS

S. de Haan and

$\mathrm{H}$. van der Marel

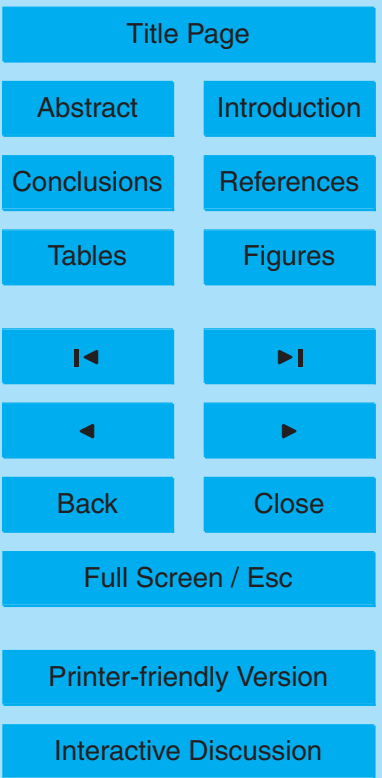


Ridal, M. and Gustafsson, N.: A bias reduction scheme and its impact on ZTD assimilation, TOUGH Deliverable D16-17, Danish Meteorological Institute, http://tough.dmi.dk, 2006. 17210

Rothacher, M. and Mervart, L.: Bernese GPS Software Version 4.0, Technical report, Astronomical Institute, Berne University, Switzerland, 1996. 17198

Saastamoinen, J.: Atmospheric Correction for the Troposphere and Stratosphere in Radio Ranging of Satellites, Geoph. Monograph Series, 15, 247-251, 1972. 17198

Stoffelen, A., Becker, B., Eyre, J., and Roquet, H.: Theoretical Studies of the Impact of Doppler Wind Lidar Data - Preparation of a database, Tech. Rep. ESA-CR(P)-3943, ESA, 1994. $10 \quad 17206$

Thayer, G.: An improved equation for the radio refractive index of air, Radio Sci., 9, 803-807, 1974. 17197

Undén, P., Rontu, L., Järvinen, H., Lynch, P., Calvo, J., Cats, G., Cuhart, J., and Eerola, K.: HIRLAM-5 Scientific Documentation, Tech. rep., HIRLAM-project, Norrköpping, $15 \mathrm{http}: / /$ hirlam.org, 2002. 17205

van der Marel, H. and Gündlich, B.: Development of Models for Use of Slant Delays, Slant Delay Retrieval and Multipath Mapping Software, TOUGH Deliverable D33, Danish Meteorological Institute, http://tough.dmi.dk, 2006. 17198, 17199, 17204

\section{ACPD}

8, 17193-17235, 2008

Three dimensional water vapour from GPS

S. de Haan and

$\mathrm{H}$. van der Marel

Title Page

Abstract

Introduction

Conclusions

Tables

References

Figures

14

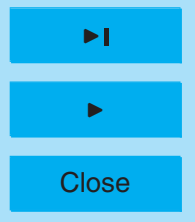

Back 


\section{ACPD}

8, 17193-17235, 2008

\section{Three dimensional water vapour from GPS}

S. de Haan and H. van der Marel

Table 1. Coefficients of the background error covariance fit as defined in Eq. (13).

\begin{tabular}{cccc}
\hline & $a_{i}$ & $b_{i}$ & $c_{i}$ \\
\hline$i=1$ & -1.726400 & $-3.19943 \cdot 10^{2}$ & $-8.212579 \cdot 10^{-1}$ \\
$i=2$ & $9.678325 \cdot 10^{-1}$ & $-2.57259 \cdot 10^{-1}$ & $2.959536 \cdot 10^{-2}$ \\
$i=3$ & $-1.62699210^{-1}$ & $4.03587 \cdot 10^{2}$ & $9.014327 \cdot 10^{-4}$ \\
\hline
\end{tabular}

Title Page

Abstract

Introduction

Conclusions

References

Tables

Figures

14

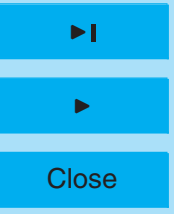

Back

Full Screen / Esc

Printer-friendly Version

Interactive Discussion 

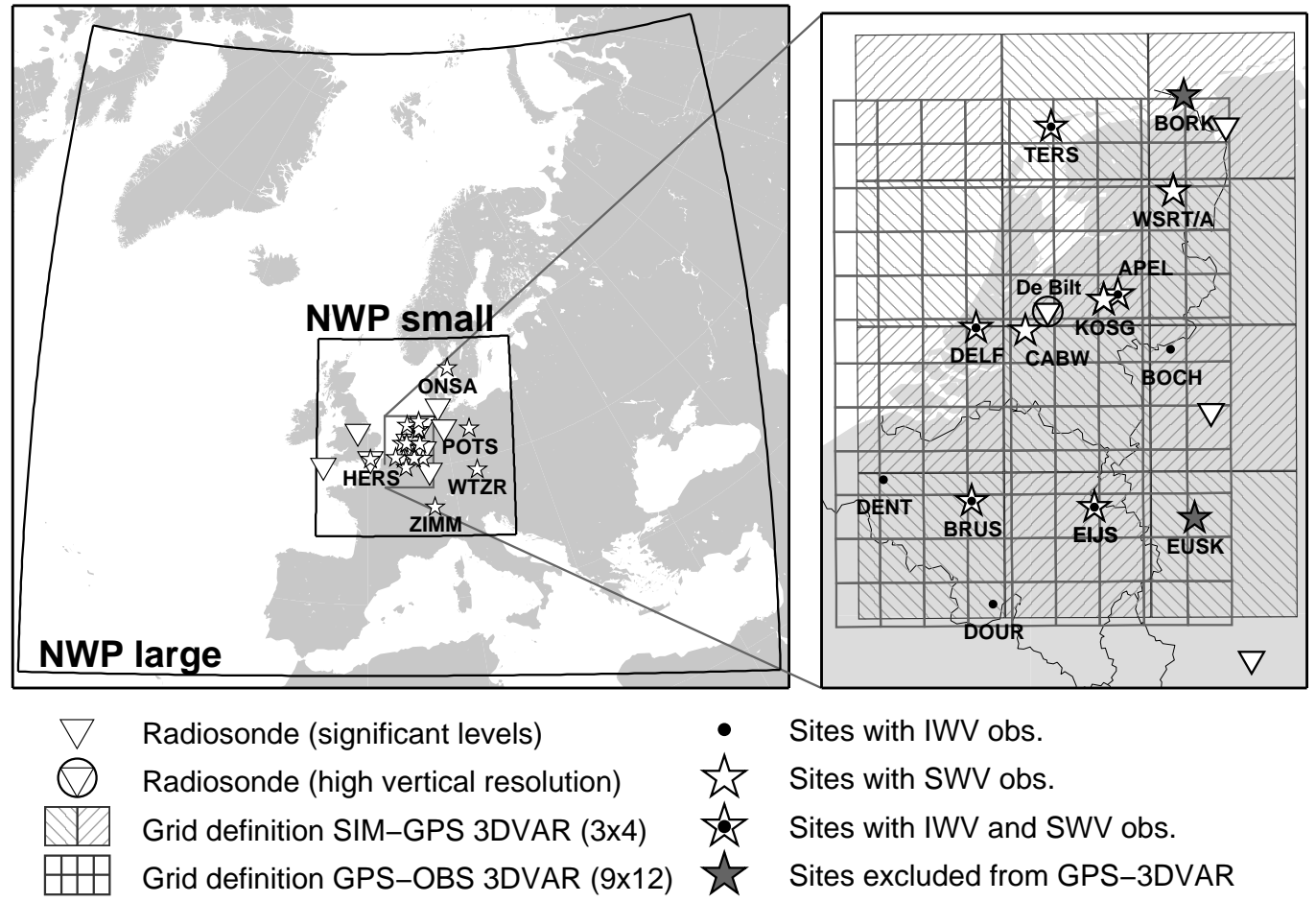

Fig. 1. The GPS network, with on the left the IGS and EPN stations involved in the network and on the right a detail of the Netherlands.

\section{ACPD}

8, 17193-17235, 2008

\section{Three dimensional water vapour from GPS}

S. de Haan and H. van der Marel

Title Page

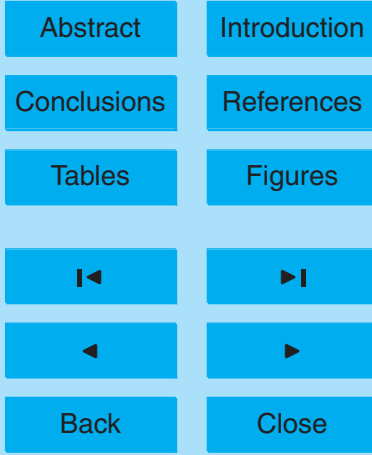

Full Screen / Esc

Printer-friendly Version

Interactive Discussion 


\section{ACPD}

8, 17193-17235, 2008

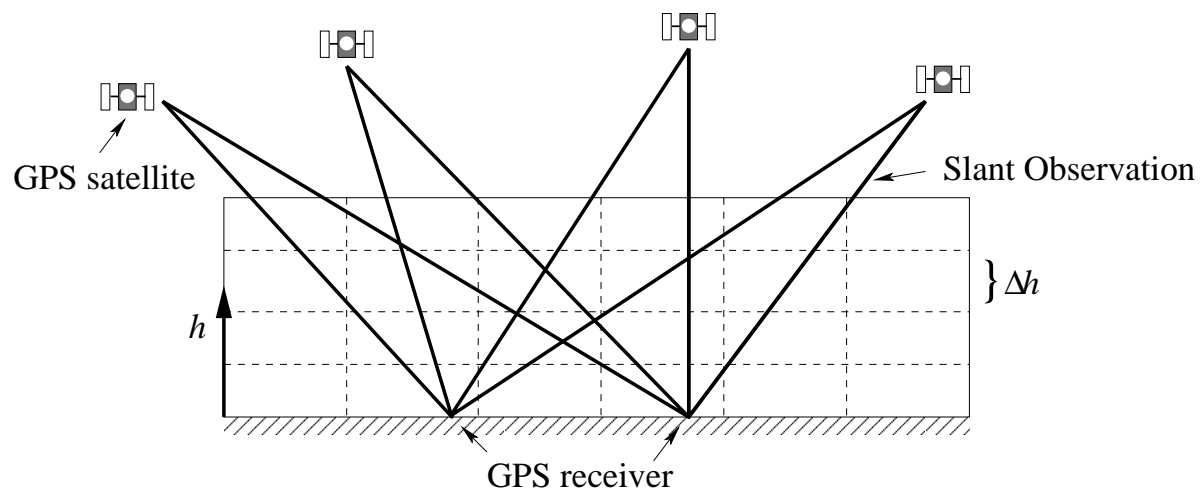

Fig. 2. Schematics representation of the three-dimensional model space.

\section{Three dimensional water vapour from GPS \\ S. de Haan and H. van der Marel}

Title Page

Abstract Introduction

Conclusions References

Tables Figures

14

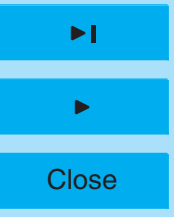

Back

Full Screen / Esc

Printer-friendly Version

Interactive Discussion 


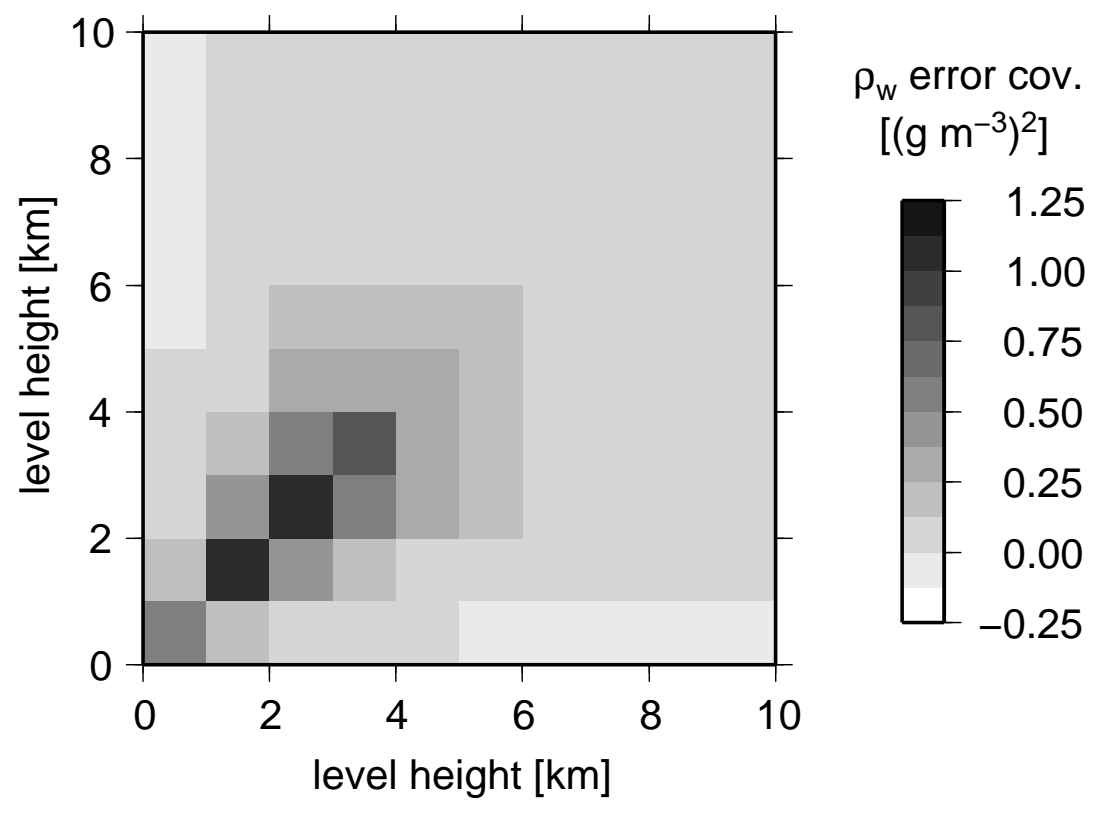

Fig. 3. Vertical water vapour density background error covariance for departures from the ECMWF $12 \mathrm{~h}$ forecast based on radiosonde observation from De Bilt for an 18 month period.
8, 17193-17235, 2008

\section{Three dimensional} water vapour from GPS

S. de Haan and H. van der Marel

Title Page

Abstract Introduction

Conclusions

References

Tables

Figures

14

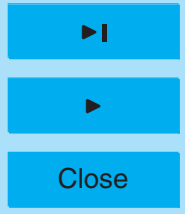

Back

Full Screen / Esc

Printer-friendly Version

Interactive Discussion 


\section{ACPD}

8, 17193-17235, 2008
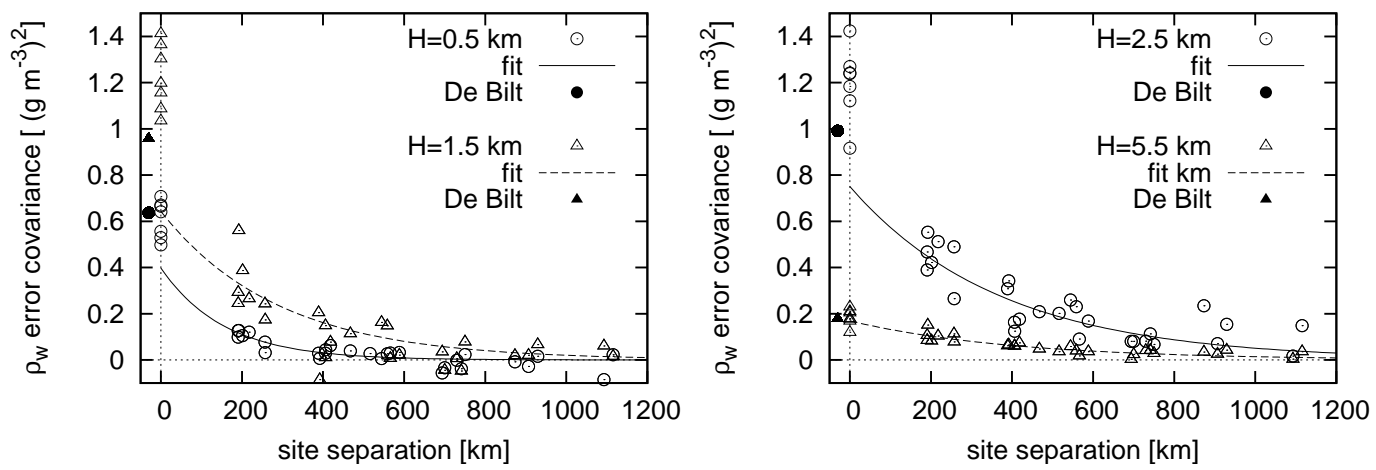

\section{Three dimensional water vapour from GPS}

S. de Haan and

H. van der Marel

\section{Title Page}

Abstract

Conclusions

Tables

14

4

Back
Introduction

References

Figures ECMWF $24 \mathrm{~h}$ forecast based on significant level radiosonde observations from 9 sites for an 18 month period. Also plotted near the y-axis is the $\rho_{w}$ error covariance (at the specific height) as determined using $10 \mathrm{~s}$ data from radiosonde De Bilt (conform Fig. 3). The solid and dashed lines is the fit of the background error covariances.

\section{Full Screen / Esc}

Printer-friendly Version 

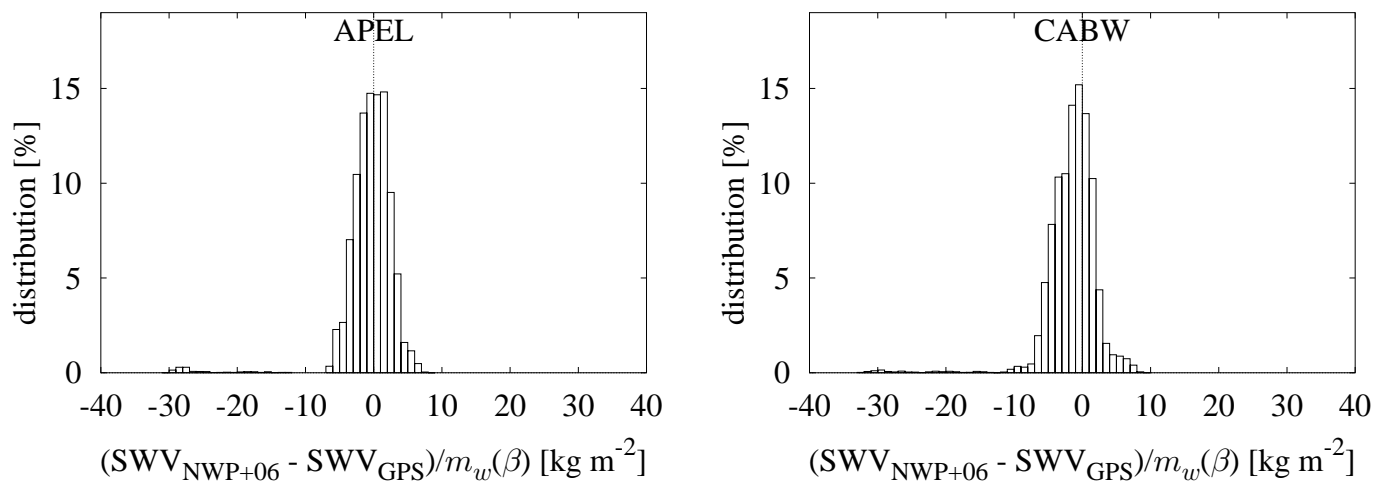

8, 17193-17235, 2008
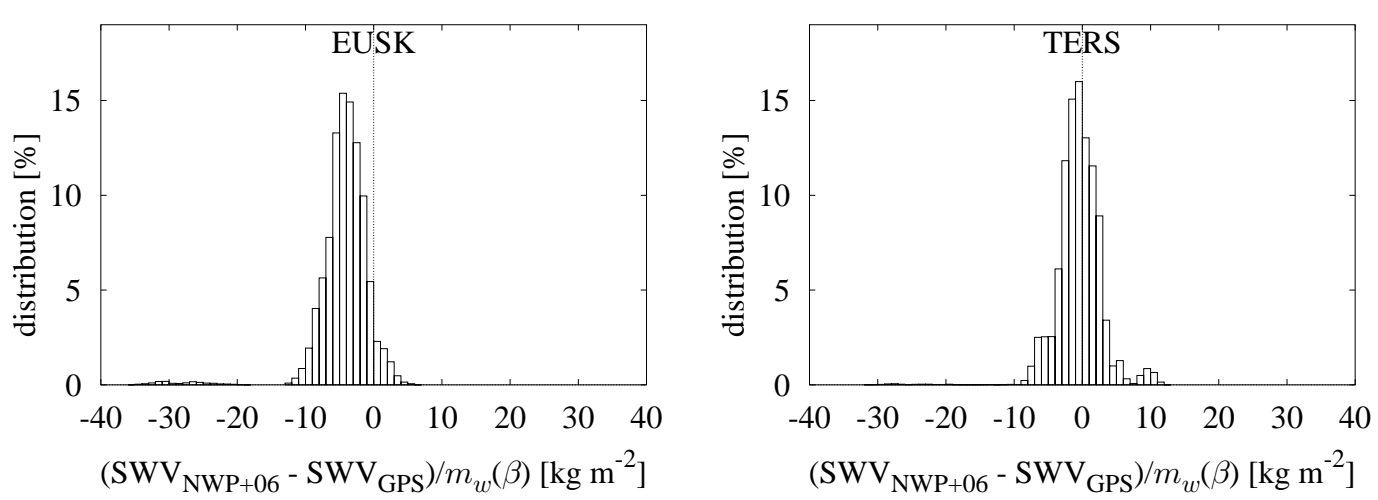

\section{Three dimensional water vapour from GPS}

S. de Haan and H. van der Marel

Title Page

Fig. 5. Distributions of the mapped difference between SWV NWP $6 \mathrm{~h}$ forecast and GPS SWV. The Niell wet mapping function is used. 


\section{ACPD}

8, 17193-17235, 2008
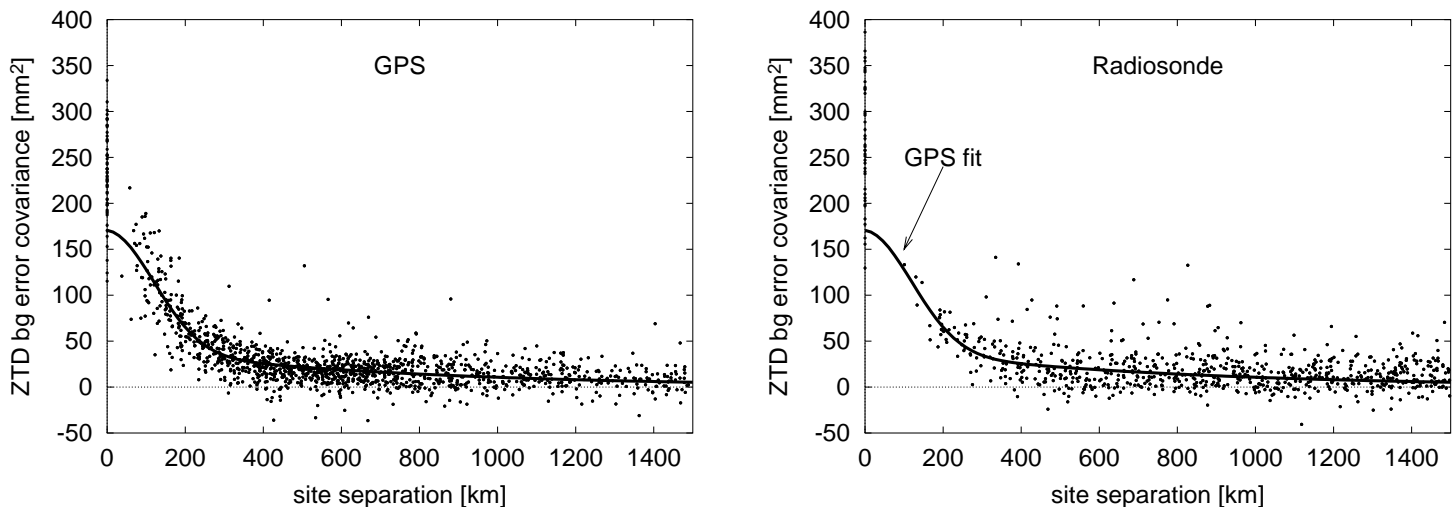

\section{Three dimensional water vapour from GPS}

S. de Haan and

H. van der Marel

Title Page

Fig. 6. Background error covariances in ZTD from (a) GPS and (b) RS with ECMWF forecast of at least $24 \mathrm{~h}$ for the period 1 July 2001 to 1 November 2002. The fit is defined by $\rho(r)=$ $126 \exp ^{-(r / 170)^{2}}+44 \exp ^{-r / 700}$.

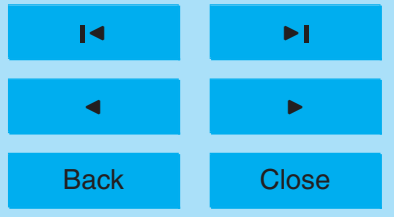

Full Screen / Esc

Printer-friendly Version

Interactive Discussion 


\section{ACPD}

8, 17193-17235, 2008

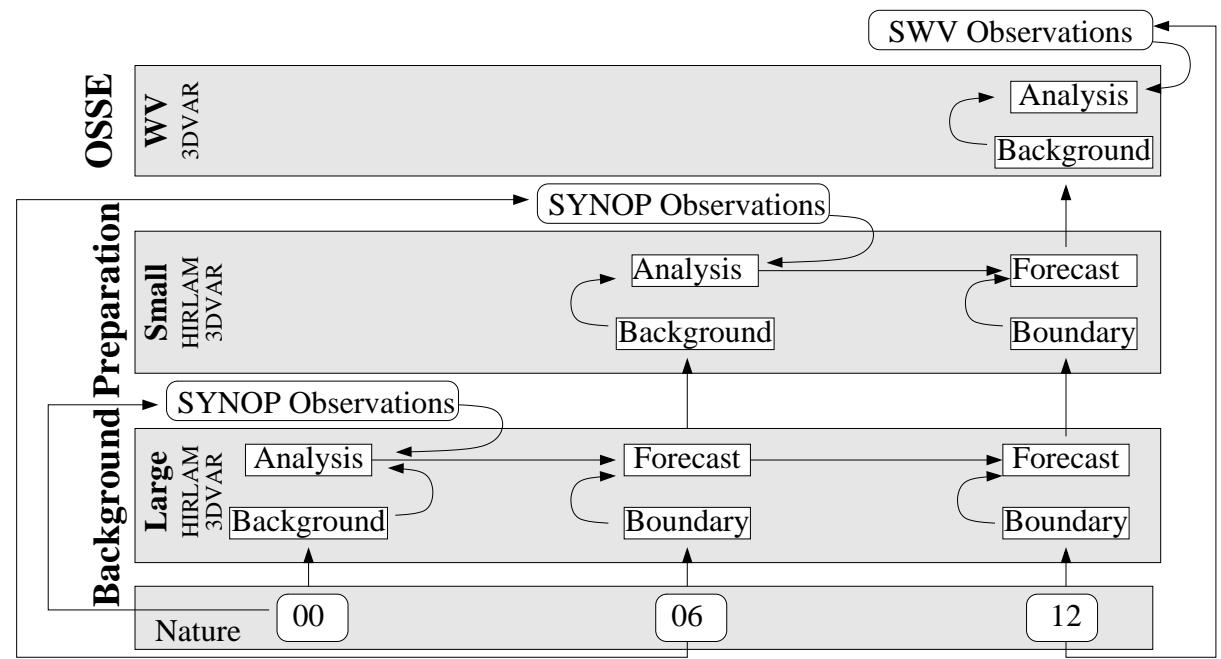

\section{Three dimensional} water vapour from GPS

S. de Haan and H. van der Marel

Title Page

Fig. 7. Schematic representation of the data flow for the simulated observation experiment.

\section{Full Screen / Esc}

Printer-friendly Version 


\section{ACPD}

8, 17193-17235, 2008

\section{Three dimensional water vapour from GPS}
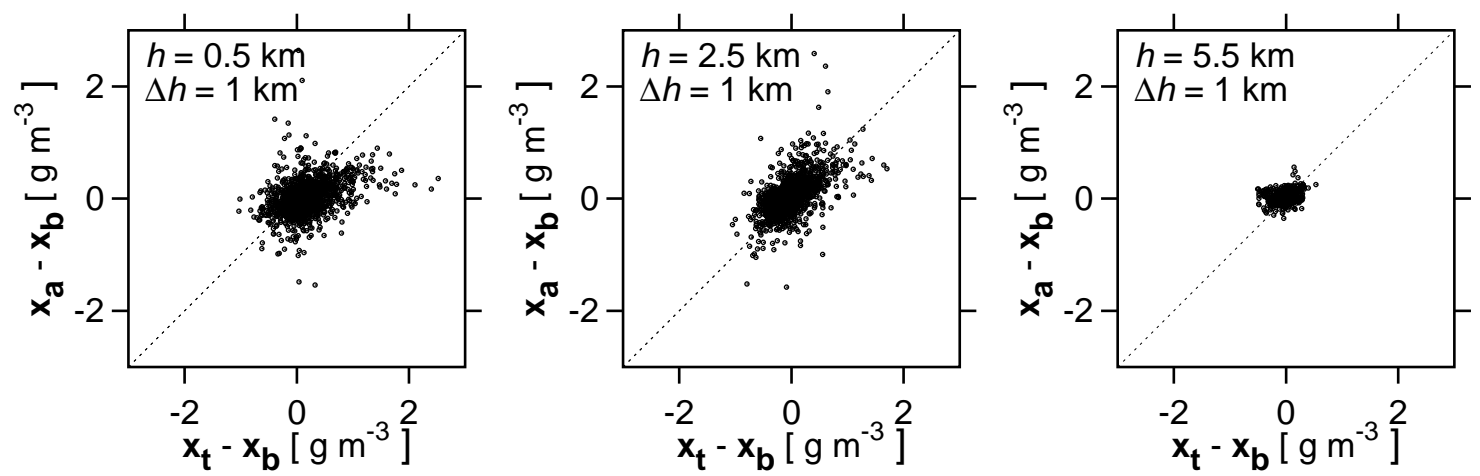

Fig. 8. Scatter plot of the water vapour difference between the truth (nature run, $x_{t}$ ) and the background $x_{b}$ against the innovation (SIM-GPS SWV solution $x$ minus background) for three selected levels.

S. de Haan and

H. van der Marel

Title Page

Abstract

Introduction

Conclusions

References

Tables

Figures

14

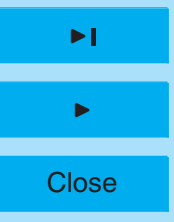

Back

Close

Full Screen / Esc

Printer-friendly Version

Interactive Discussion 


\section{ACPD}

8, 17193-17235, 2008
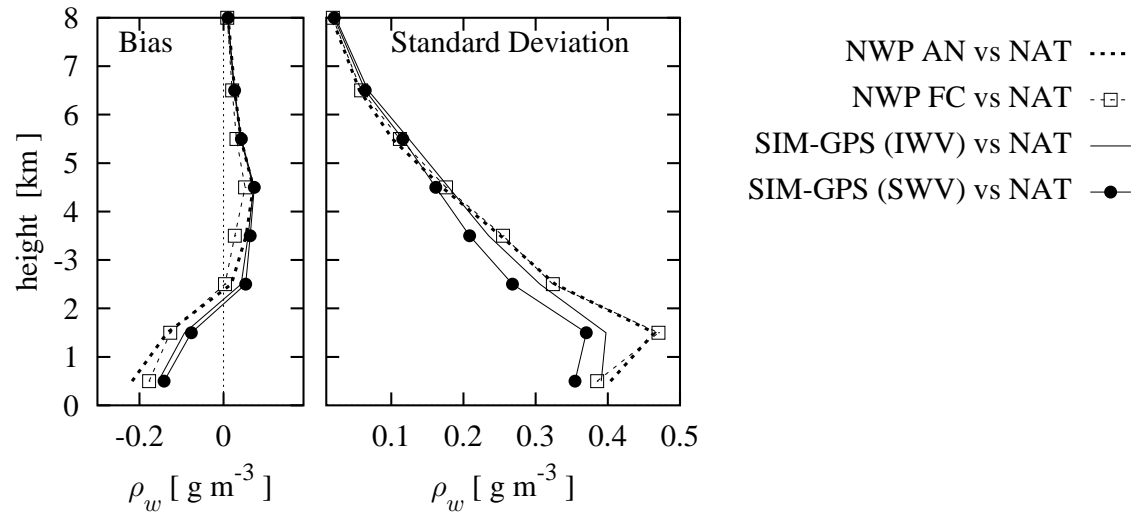

Three dimensional water vapour from GPS

S. de Haan and

H. van der Marel

Fig. 9. Statistics of the water vapour difference between truth (nature run) and SIM-GPS SWV (solid line with solid circles), SIM-GPS IWV (solid line), NWP analysis (dashed line) and NWP forecast (dashed line with boxes), respectively.

Title Page

Abstract

Introduction

Conclusions

References

Tables

Figures

14

$\rightarrow$

4

Back

Close

Full Screen / Esc

Printer-friendly Version

Interactive Discussion 


\section{ACPD}

8, 17193-17235, 2008
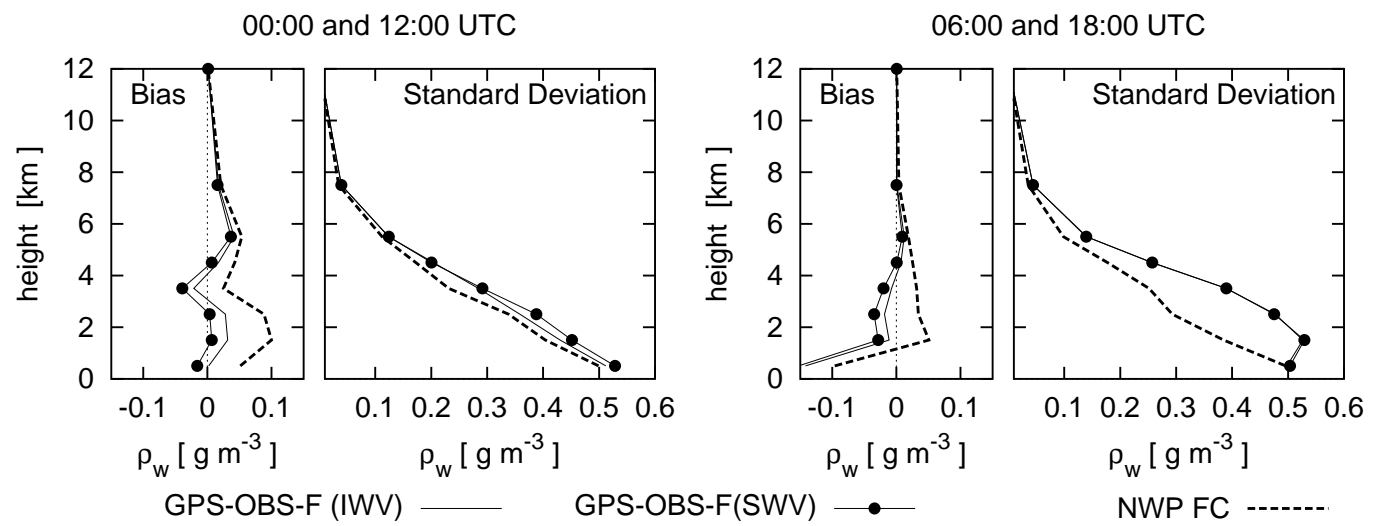

\section{Three dimensional water vapour from GPS}

S. de Haan and

H. van der Marel

Fig. 10. Statistics of the water vapour difference between NWP analysis and OBS-GPS-F SWV (solid lines with circles), IWV (solid lines) and NWP 6-h forecast (dashed line) for two different time pairs: left panel shows the difference at 00:00 and 12:00 UTC, right panel 06:00 and 18:00 UTC.

Title Page

Abstract

Introduction

Conclusions

References

Tables

Figures

14

$\rightarrow$

4

Back

Close

Full Screen / Esc

Printer-friendly Version

Interactive Discussion 


\section{ACPD}

8, 17193-17235, 2008

De Bilt

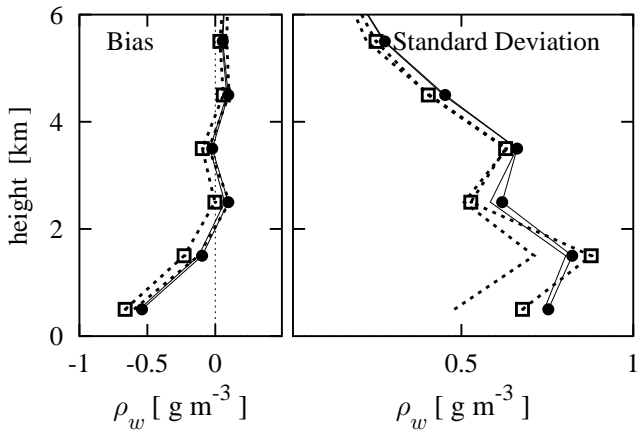

Cabauw

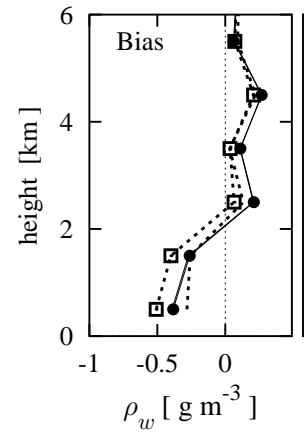

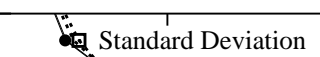

S
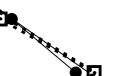

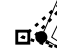

Q.8.
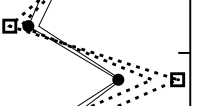

RS - (GPS-OBS-F IWV) — RS - (GPS-OBS-F SWV)

\section{Three dimensional water vapour from GPS}

S. de Haan and

H. van der Marel

\section{Title Page}

Abstract Introduction

Conclusions

References

Tables

Figures

Fig. 11. Bias and standard deviation between radiosonde water vapour observations and NWP analysis/forecast and GPS-OBS-F (IWV/SWV with NWP background): left panels radiosonde De Bilt, right panels radiosonde Cabauw. The dashed line represents the bias and standard deviation from NWP analysis; dashed line with boxes is the bias and standard deviation from NWP forecast; solid line with circles show the statistics from GPS-OBS-F SWV; the solid line the statistics of OBS-GPS-F IWV.

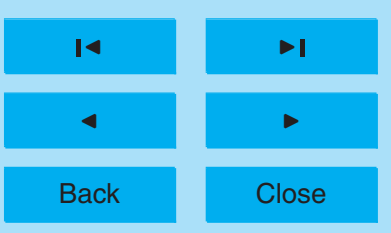

Full Screen / Esc

Printer-friendly Version 


\section{ACPD}

8, 17193-17235, 2008
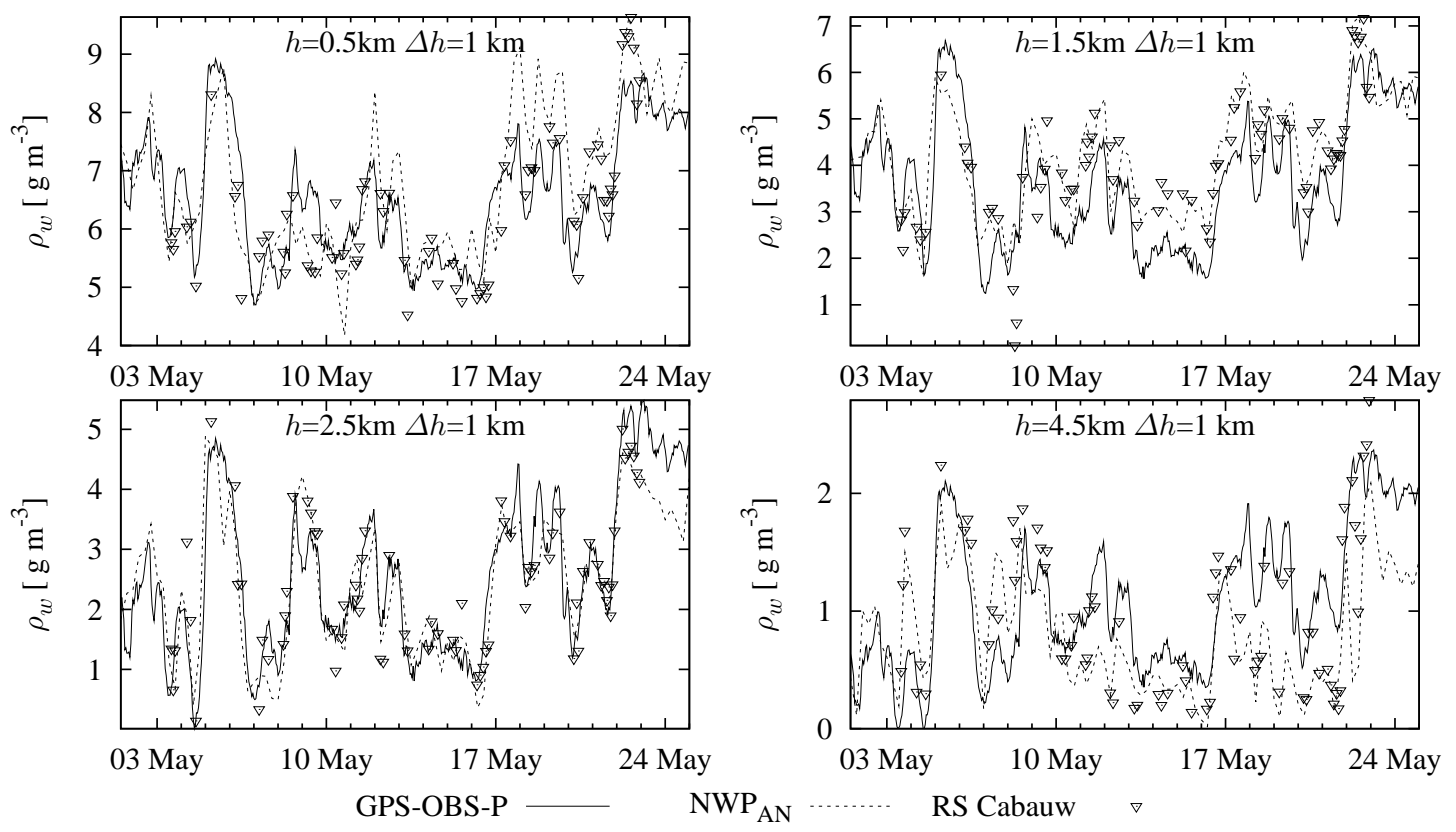

Fig. 12. Water vapour time series at location Cabauw of OBS-GPS-P (SWV) (solid line), operational NWP analysis (dashed line) and Radiosonde Cabauw (stars) at four selected heights.

\section{Three dimensional water vapour from GPS}

S. de Haan and H. van der Marel

Title Page

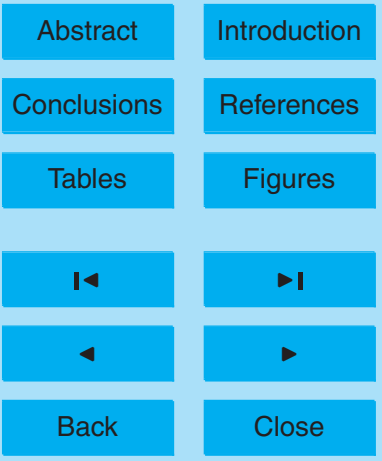

Full Screen / Esc

Printer-friendly Version

Interactive Discussion 


\section{ACPD}

8, 17193-17235, 2008

De Bilt

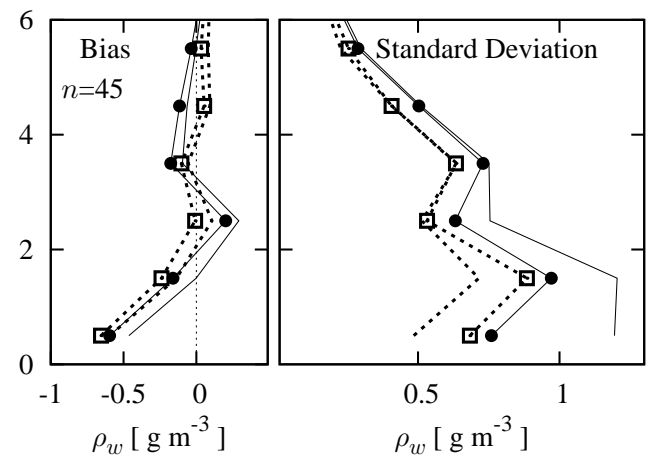

RS - (GPS-OBS-P IWV) — RS - (GPS-OBS-P SWV)
Cabauw
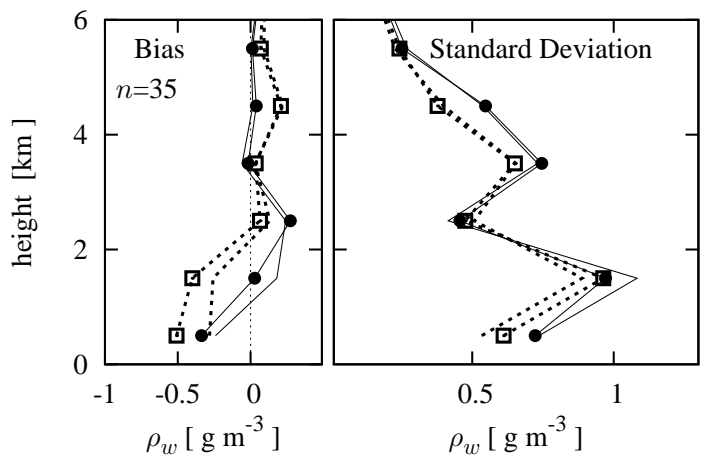

$\mathrm{RS}-(\mathrm{NWP}$ AN) $\quad \cdots \quad$ RS - (NWP BG) $\cdot$ • $\cdot$

\section{Three dimensional water vapour from GPS}

S. de Haan and

H. van der Marel

\section{Title Page}

Abstract

Introduction

Conclusions

References

Tables

Figures

14

$>1$

4

Back

Full Screen / Esc

Printer-friendly Version

Interactive Discussion 


\section{ACPD}

8, 17193-17235, 2008

\section{Cabauw}

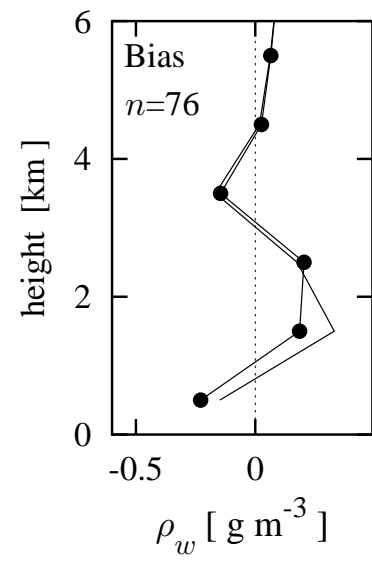

RS - (GPS-OBS-P IWV)

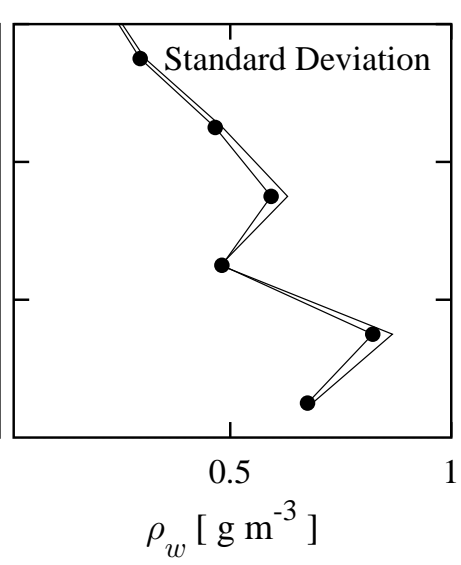

RS - (GPS-OBS-P SWV)

\section{Three dimensional} water vapour from GPS

S. de Haan and

$H$. van der Marel

\section{Title Page}

\section{Abstract}

Conclusions

\section{Tables}

14

4

Back
Introduction

References

Figures

$\rightarrow$

Fig. 14. Bias and standard deviation between all radiosonde water vapour observations Cabauw 3DVAR-GPS (IWV/SWV with background from previous hour) for radiosonde Cabauw. The solid line with circles show the statistics from 3DVAR-GPS SWV and the solid line the statistics of OBS-GPS-P IWV.

\section{Full Screen / Esc}

Printer-friendly Version 

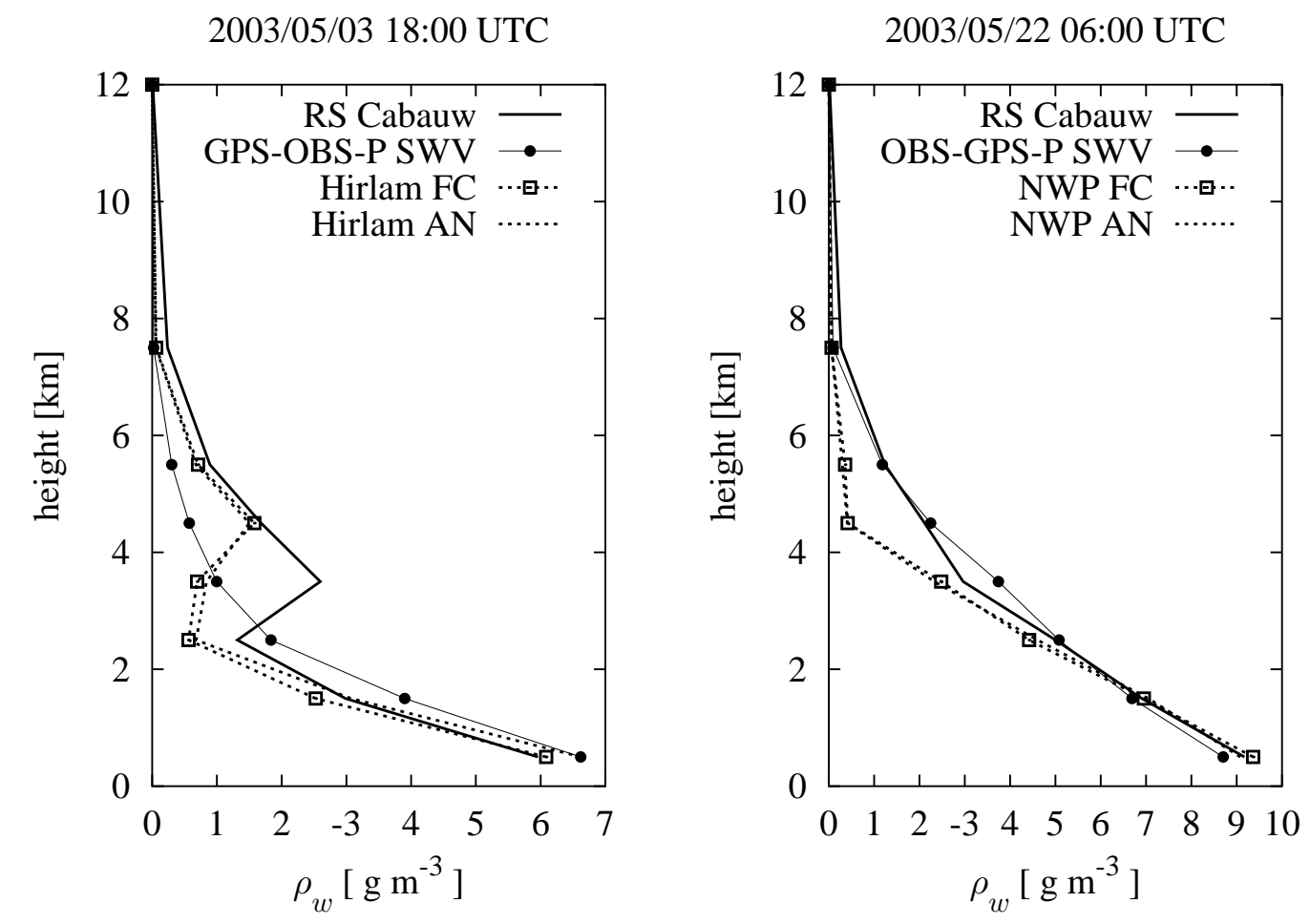

8, 17193-17235, 2008

Three dimensional water vapour from GPS

S. de Haan and

H. van der Marel

Title Page

Abstract

Introduction

Conclusions

References

Tables

Figures

14

$>1$

4

Back

Close

Full Screen / Esc

Fig. 15. Water vapour profile of NWP(analysis and forecast), OBS-GPS-P (SWV) and radiosonde observations at Cabauw at (a) 3 May 2003 18:00 UTC and (b) 22 May 2003 06:00 UTC.

Printer-friendly Version

Interactive Discussion 